University of Rhode Island

DigitalCommons@URI

Open Access Dissertations

1995

\title{
The Pursuit of Beauty Through Thinness and the Impact of Advertising on College Women's Attitudes
}

Lisa Marie Rocchio

University of Rhode Island

Follow this and additional works at: https://digitalcommons.uri.edu/oa_diss

\section{Recommended Citation}

Rocchio, Lisa Marie, "The Pursuit of Beauty Through Thinness and the Impact of Advertising on College Women's Attitudes" (1995). Open Access Dissertations. Paper 1072.

https://digitalcommons.uri.edu/oa_diss/1072

This Dissertation is brought to you for free and open access by DigitalCommons@URI. It has been accepted for inclusion in Open Access Dissertations by an authorized administrator of DigitalCommons@URI. For more information, please contact digitalcommons-group@uri.edu. 
THE PURSUIT OF BEAUTY THROUGH THINNESS

AND THE IMPACT OF ADVERTISING ON

COLLEGE WOMEN'S ATTITUDES

BY

LISA MARIE ROCCHIO

A DISSERTATION SUBMITTED IN PARTIAL FULFILLMENT OF THE REQUIREMENTS FOR THE DEGREE OF DOCTOR OF PHILOSOPHY

IN

PSYCHOLOGY

UNIVERSITY OF RHODE ISLAND

1995 


\section{Abstract}

This experimental study examined the impact of exposure to advertisements that did or did not depict attractive female models on the self-esteem, attitudes toward the body, bodysatisfaction, and figure-ratings of college women with high or low levels of eating-disordered and gender-stereotypical behavior. In addition, a scale measuring attitudes and behaviors consistent with women's pursuit of beauty was developed, and its preliminary factor structure was assessed. A total of 180 predominantly European-American, heterosexual college students (122 women and 58 men) participated in the study. Results did not differ for women who participated in mixed-gender or single-gender groups. Women exposed to advertisements depicting female models, when compared to women exposed to advertisements not depicting models, rated their own body-size as larger. Exposure to advertisements depicting female models had no significant impact on ratings of attitudes toward the body, body-satisfaction, or self-esteem. Attitudes toward their bodies were more negatively impacted by exposure to models among those women with higher levels of eating-disordered attitudes and behaviors and greater endorsement of genderstereotyping. Significant correlations were found among measures of eating attitudes and behaviors, beauty attitudes, attitudes consistent with gender stereotypes, body image, and self-esteem for both women and men. However, 
the patterns of these relationships differed. Women scored significantly higher on measures of eating disorders and significantly lower on measures of gender-stereotyping and endorsement of positive attitudes toward the body than did men. Men's attitudes toward women's bodies were not affected by exposure to female models in advertisements. 


\section{Acknowledgments}

This study could not have been accomplished without the help and guidance of a great number of people, individuals to whom I am extremely grateful.

My major professor, Bernice Lott, has been a mentor and a friend throughout my graduate training, and I have been truly fortunate to have had her enthusiasm, intellectual rigor, and support. I thank other members of my doctoral committee for their insightful and valuable contributions to this project. Patricia Morokoff, for her contributions in the planning of this project, her clarity of clinical thought, and her modeling of the integration of clinical theory and research; Joan Chrisler, for her keen eye and knowledge about women's pursuit of beauty, as well as her frequent availability to consult on all aspects of this project; and Barbara Luebke, for her insights into the advertising industry and media, and for her journalistic guidance. I also thank the additional members of my defense committee. Iynn Pasquerella for her comments relating to philosophy of science and ethics; and David Faust for his sharp wit, contributions to the development of my critical thinking skills, and his astute clinical insight. His support and encouragemet have kept me progressing steadily in my professional development.

A special thanks goes to the professors who helped with the recruitment of participants, and to the students who 
gave of their time to participate in this study. Without them, this research would not have been possible.

I am deeply grateful to the wonderful network of friends who have offered tremendous support during my graduate training. In particular, I thank Colleen Gregory for her depth of thought and for the warmth of her friendship. Much appreciation goes to my parents for their generosity and support. They instilled in me the determination and self-confidence to embark on a career in psychology, and the courage to stand up for my beliefs. I thank my brother, Anthony, whose energy and creativity have served as an inspiration to me. Finally, and most of all, I thank my husband, Vincent, for his endless love, comfort, and enthusiasm, and for his ability to make me laugh. 
Table of Contents

Abstract..............................

Acknowledgments........................... iv

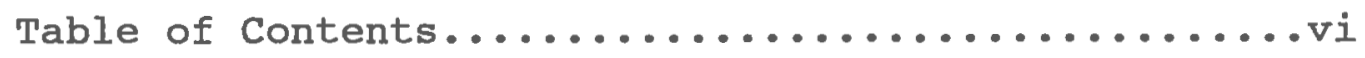

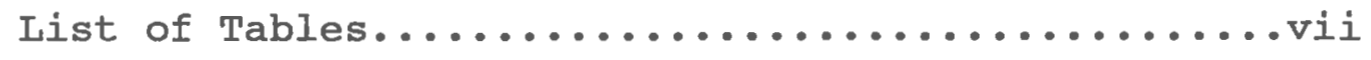

Introduction............................

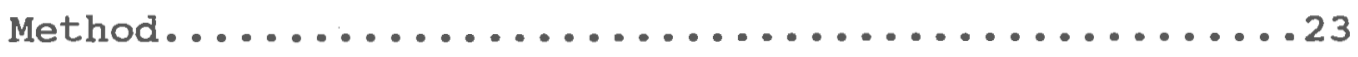

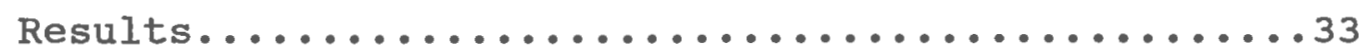

Discussion..............................60

Appendix A.................................

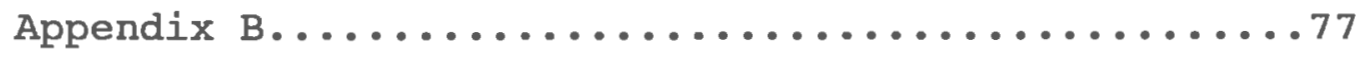

Bibliography.............................. 102 
List of Tables

1. Means and standard deviations

of women's scores in model/no-model

and mixed-gender/single-gender

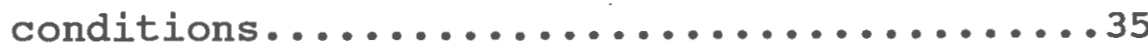

2a. Correlations of pre-test measures

for women.........................40

2b. Correlations of pre-test measures

for men..........................41

3. Means and standard deviations of women's

scores in high-eating/low-eating and

high-stereotyping/low-stereotyping

conditions........................46

4. Means and standard deviations of men's

scores in model/no-model conditions.......51

5. Women's and men's means and standard

deviations on pre-test measures..........53

6. Beauty questionnaire items and factor

loadings for retained items...........57 


\section{INTRODUCTION}

\section{Fat oppression}

Fat oppression is "hatred and discrimination against fat people, primarily fat women, solely because of their body size" (Brown \& Rothblum, 1989, p. 1). Fat oppression negatively impacts the lives of all women, but primarily those women who do not meet the "thin ideal" of modern Western culture (Rothblum, 1992). Cahnman's (1968) observation almost thirty years ago that "being overweight is considered to be detrimental to health, a blemish to appearance, a social disgrace [and] . . morally reprehensible" (p. 283) is perhaps even more true today.

Professionals who work on obesity endorse negative stereotypes about fat people, e.g.,fat people lack willpower, are self-indulgent, do not care about their appearance, and have emotional difficulties (Maiman, Wang, Becker, Finlay, \& Simonson, 1979). Mental health professionals attribute greater degrees of psychopathology to fat women than to thin ones (Young \& Powell, 1985). Psychologists asked to respond to case histories rated fat clients in general as more physically unattractive and more embarrassed as well as kinder and softer than non-fat clients (Agell \& Rothblum, 1991). Brown (1989) argues that even feminist therapists continue to hold fat-oppressive attitudes toward their clients.

In general, fat people are rated as less intelligent, 
less successful, and less desirable as an employee than thin people (Larkin \& Pines, 1972; Rothblum, Miller \& Garbutt, 1988). A study by Miller, Rothblum, Barbour, Brand, and Felicio (1990) found that fat women were liked less, made a poorer impression, and were rated as both less socially skilled and less physically attractive than non-fat women. Miller and Rothblum (1990) recruited obese and non-obese women and had them participate in telephone conversations with college students who were unaware of the weights of their phone partners. Obesity was defined as greater than 208 over the midpoint of average weight for height on Metropolitan Life Insurance Company Tables. Judges who were also unaware of women's actual weights listened to audiotapes of the phone conversations and rated the women on factors such as likability, social skills, and physical attractiveness. Though judges were unaware of the actual body size of the women conversing, obese women were judged more negatively. In addition, the college student telephone partners of obese women rated themselves and their phone partners more negatively than did the telephone partners of non-obese women. Thus, obesity seems to have a negative impact on the social interactions of obese women, as rated by participants in phone conversations and judges of the phone conversations, even when the weight of the woman is masked. Allon (1976) found that adolescent girls perceived their fat to be a handicap in social interactions, in that 
they believed they were degraded in social interactions due to the stigma of their weight.

In addition to being perceived negatively and stereotyped, fat people are actively discriminated against. Landowners are less likely to rent to fat people (Karris, 1977), and fat students, especially fat women, are less likely to be accepted into prestigious colleges (Canning \& Mayer, 1966). Fat college students are also less likely to receive financial help from their parents than are thin students, and this is especially true for women (Crandall, 1991). Furthermore, an individual's weight is likely to influence hiring decisions (Larkin \& Pines, 1979). Such discrimination may clearly account in part for the positive correlation between low socioeconomic status and obesity in the United States, which has been documented by Sobal and Stunkard (1989). Rothblum (1994) presents a convincing argument for her conclusion that "obese women become downwardly socially mobile because of their weight" (p. 61). (For a thorough analysis of the stigma of women's weight and its social and economic consequences, see Rothblum, 1992 and Rothblum, 1994).

\section{Prevalence of eating problems}

Although fat people of both genders are discriminated against, the condition of being "overweight" has a greater negative impact on women than on men, which results in women holding more negative attitudes toward themselves than men 
do (Stake \& Lauer, 1987). In addition, fat oppression negatively impacts on girls and women of all sizes, which leads to eating problems and body hatred among diverse samples of girls and women. A study of 337 adolescent girls and 424 adolescent boys found that the girls were significantly more concerned with their weight; overall, they demonstrated a pattern of marked concern with weight, and engaged in undesirable/unhealthy eating behaviors in their efforts to lose weight (Greenfeld, Quinlan, Harding, Glass, \& Bliss, 1987). Women of all sizes, in comparison to men, report significantly greater concern with their weight, and although fat people of both genders are perceived negatively, fat women are perceived more negatively than fat men (Tiggemann \& Rothblum, 1988). Women tend to overestimate their body size, and to believe that they are fat when in fact they are of average or below average weight for their height (Thompson, 1986; Tiggeman \& Rothblum, 1988). Women's weights are also much more variable over time than are men's, a likely consequence of women's dieting behavior (Lissner, Odell, D'Agostino, Stokes, Kreger, Belanger, \& Brownell, 1991).

Unhealthy eating and negative attitudes toward one's body are pervasive among women in U.S. society, and weight concerns and dieting are now so common among girls and women that they are considered normative (Polivy \& Herman, 1985; Polivy \& Herman, 1987; Rodin, Silberstein, \& Streigel-Moore, 
1985). Chronic dissatisfaction with bodies is at epidemic levels among women. Mintz and Betz (1988) found that 828 of their sample of 643 college women reported one or more dieting behaviors on at least a daily basis. A 1987 survey found that $63 \%$ of high school girls reported that they were on diets (Rosen \& Gross, 1987). A 1984 survey of women readers of Glamour magazine found that women identified a 10- to 15-pound weight loss as more desirable than love or professional success (Wooley \& Wooley, 1984).

Women certainly vary in the degree to which they pursue thinness, but the majority of women in the United States actively engage in some form of unhealthy behavior in order to achieve a thin ideal. Eating disorders do not just impact a minority of women who differ substantially from the general population. Rather, there is evidence to support the existence of an "eating disorder continuum," which ranges from no concern with weight, accompanied by normal eating, to anorexia or bulimia nervosa. The middle of the continuum can be characterized by unhealthy eating behavior such as bingeing or purging, fasting, and chronic dieting (Mintz \& Betz, 1988; Polivy \& Herman, 1987). The further along the continuum, the more severe and life threatening are the consequences. Although just 38 of a sample of 643 undergraduate women studied by Mintz and Betz (1988) were found to meet DSM III-R criteria for bulimia nervosa, only $33 \%$ reported "normal" eating behaviors, and $61 \%$ were 
classified as having some intermediate level of eating problem.

Although eating-disordered behavior has been generally thought to be a European-American, upper-middle-class phenomenon, recent data suggests that this is not the case. Studies of African American, Latina, and Native American young girls and women have found these groups to be at risk for the development of eating disorders (Abrams, Allen, \& Gray, 1993; Root, 1991; Rosen, Shafer, Dummer, Cross, Deuman, \& Malmberg, 1988; Smith \& Krejci, 1991).

A survey of 85 Native American girls and women found that $74 \%$ were actively trying to lose weight, and that of those who were dieting, $75 \%$ were employing unhealthy and potentially dangerous methods such as skipping meals, using laxatives, diet pills or diuretics, restricting fluid intake, fasting, or vomiting (Rosen et al., 1991). Another study, which compared eating behaviors among 535 Native American, Hispanic, and European-American high school students, found that the Native American students consistently scored higher on items that measured disturbed eating behaviors and attitudes. The Hispanic students were also found to have high rates of problematic attitudes and behaviors, and the authors concluded that "the rate of disturbed eating patterns among Native American as well as Hispanic youth is at least comparable to that of white adolescents" (Smith \& Krejci, 1991, p. 184). A 1990 survey 
of a random sample of 2,115 adults in the general population found no ethnic differences in the prevalence of bulimia nervosa (Rand \& Kuldau, 1992).

Root (1990) has pointed out that individuals within ethnic minority groups are subjected to the prevailing norms and societal dictates of the dominant European-American culture. Therefore, women of color may be at greater risk for the development of eating disorders than previously believed. In addition, much of the research in the area of eating disorders has been done with predominantly European American participants, which may have resulted in an underestimation of the degree of eating disturbances among women of color.

Neither eating concerns nor body hatred are limited to financially affluent women. Levenkron (1982) concluded that "the spectrum [of eating disorders] has been expanded to encompass all socioeconomic levels" (p. 1), and Gibbs (1986) failed to find a relationship between socioeconomic status and degree of disordered eating behavior in a study of high school students. A study of social class and anorexia nervosa by Gowers and McMahon (1989) found that although there was a skew toward higher socio-economic classes, it was much less marked than in a study conducted 10 years ago. One study (Rand \& Kuldau, 1992) found self-reported bulimia to be more prevalent among participants from low socioeconomic classes than among those from high 
socioeconomic classes.

The high frequency of dieting behavior by women across ethnic and socioeconomic groups is particularly alarming when one considers that $95 \%$ to $98 \%$ of all diets fail (Fitzgerald, 1981; Stunkard, 1958). In a review of the results of a stratified random sample of 50 weight-loss studies appearing in psychological journals, Cogan and Rothblum (1993) found that the average participant in a weight loss program weighed only 9.7 pounds less 10 months after beginning the weight loss program. Further, not a single study tested the assumption that weight loss resulted in greater physical health. The investigators concluded that "given the lack of effectiveness of weight-loss programs, psychologists may be perpetuating a problem rather that providing a solution" (p. 411). As a result of the promotion of dieting as a cure for fat, women spend large sums of money on diet foods, programs, books, etc., supporting the 30 to 33 billion dollar per year dieting industry (Brownell, 1991; Wolf, 1991). Women are thus robbed of money that could be better spent on more productive and self-nurturing activities (Brown, 1989).

Chrisler (1989) has pointed out that the pursuit of beauty has been co-opted by the health industry. She argues that the cultural insistence on the pursuit of health has resulted in the increasing popularity of health food stores, running shoes, and vitamins. Such an emphasis on health has 
elevated the pursuit of beauty to a new moral creed: "I eat right, watch my weight, and exercise" (Seid, 1994, p. 4). Paradoxically, the stigmatization of fat in U.S. culture may actually function to reduce the involvement of fat people (or those who believe they are fat) in healthful activities such as exercise (Packer, 1989). Factors such as the fear of ridicule from others, inability to find comfortable exercise clothing, lack of financial resources, and difficulty keeping up with others can be powerful motivators not to exercise (Packer, 1989).

In spite of the emphasis on the pursuit of thinness as a means to improve health, there is significant evidence to support the opposite conclusion, namely, that dieting and the pursuit of thinness is harmful to emotional and physical well-being, and that fat, in and of itself, is not necessarily harmful. The relationships among fat and various physical illnesses are far more complex than is generally recognized. Ernsberger and Haskew (1987) have documented more than 30 physical illnesses in which fat functions as a protective factor. For example, obesity is associated with a decreased incidence of osteoporosis and hip fractures in women, with a decreased incidence of tuberculosis, and with a decreased incidence of lung cancer in men. Fitzgerald (1981), in her review of the literature on obesity, concluded that there may be medical and other advantages to obesity. For example, she pointed out that fat individuals 
have a better prognosis for recovery from tuberculosis and cancer, and are more likely to survive a famine.

Apart from the ineffectiveness of weight-loss diets, and the lack of research supporting the assumption that fat is necessarily harmful, dieting has numerous physical and emotional consequences (See Bennet \& Gurin, 1982 or Polivy \& Herman, 1983 for a review). For example, a study of 9-year old girls found that those who restrained their eating reported more hunger, greater thirst, and less perceived control over their eating. In addition, they consumed $11 \%$ fewer calories than recommended for their age, and ate significantly less dietary fiber than those who did not restrain their eating (Hill \& Robinson, 1991). Keys, Brozek, Henschel, Mickelson, and Taylor (1950) examined the effects of reducing the caloric intake of a sample of men to 1,600 calories per day for 24 weeks. They found that dieting resulted in negative mood, irritability, increased obsessive thoughts of food, and decreased energy.

Repeatedly losing and regaining weight places a significant amount of strain on the body, and has been found to be harmful. A study of more than 5,000 women and men over 32 years found that weight variability was positively associated with total mortality, morbidity due to coronary heart disease, and mortality from coronary heart disease (Lissner et al., 1991). The relationships between weight cycling and mortality and morbidity held true even when 
total body mass, gradual weight gain over time, and other coronary risk factors such as smoking, exercise, and serum cholesterol level were taken into account. This relationship was strongest and most consistent in those ranging in age from 30 to 44 , which is also the group most likely to be dieting (Lissner et al., 1991). Lissner and his colleagues concluded that dieting may have a role in the development of chronic disease, and that "the risks due to excess weight may not exceed the risks due to weight fluctuation" ( $p$. 1843). The above research makes it clear that many women spend much of their lives dieting and coping with high levels of body dissatisfaction in the pursuit of thinness, beauty, and health, only to end up suffering from physical and emotional consequences of dieting and other unhealthy eating behaviors such as the use of laxatives, diuretics, and appetite suppressants. As Fitzgerald (1981) and Lissner et al. (1991) have both concluded, treatment of obesity may have more health consequences than fatness itself.

\section{Pursuit of thinness as a cultural phenomenon}

Although thinness worship is common in Western society, it is by no means universal. Anorexia nervosa has been described as a "culture bound syndrome" (Swartz, 1985), women's concern with body weight as a "fad" (Rothblum, 1990), and obesity as a "social phenomenon" (Cahnman, 1968). Within the United States the standard of beauty has changed and moved toward a thinner and thinner ideal over time (see 
Mazur, 1986, Rothblum, 1990, or Saltzberg \& Chrisler, 1994, for a review). Women's bodies are expected to change along with cultural standards of beauty (Saltzberg \& Chrisler, 1994). Garner, Garfinkel, Schwartz, and Thompson (1980) examined the published body measurements of Playboy centerfold models and Miss America contestants between 1959 and 1979. They found that the ideal body type for women became progressively thinner over time, with the most marked shift between 1969 and 1979. They also found that winners of the Miss America pageant were frequently thinner than other contestants. They also pointed out that this shift toward a thinner ideal occurred while the body size of the average woman increased.

Wiseman, Gray, Mosimann, and Ahrens (1992), in a replication and expansion of the 1980 study by Garner and colleagues, examined the body measurements of Playboy magazine centerfolds and Miss America contestants from 19791988. They found that between 1979 and 1988 the Miss America contestants decreased in body size and the body size of Playboy centerfolds stabilized at a low body weight. In addition, the body weights of the women were 138 to 198 lower than expected weights for their age group, and 698 of the Playboy centerfolds and $60 \%$ of the Miss America contestants reported weights $15 \%$ or more below the expected weights for their height and age categories. Wiseman and her colleagues concluded that the cultural ideal for women's 
body size has reached anorexic levels. Rosenzweig and Spruill (1987) found that a sample of women who were college freshmen in 1965 reported currently engaging in significantly more extreme weight control behaviors and binge eating than they had during their college years. The prevalence of body dissatisfaction and eating disordered attitudes and behaviors is higher in the United States than in other societies. A comparison of students in the United States and Ghana found that students in Ghana reported a larger ideal body size. Ghanaian students also reported a significantly wider range of ideal body sizes than those reported by U.S. students. In addition, the U.S. sample made more positive attributions about thin people than the Ghanian sample, and they reported higher levels of eating restraint and eating disordered attitudes and behaviors (Cogan, Bhalla, Sefa-Dedeh, \& Rothblum, in press). When compared with North American samples, girls and women in East and West Berlin had lower mean scores on the Eating Attitudes Test, a scale of attitudes and behaviors associated with anorexia nervosa (Newmarker, Dudeck, Vollrath, Newnarker, \& Steinhausen, 1992). Similarly, a sample of Australian women reported lower rates of eating disordered behavior and body dissatisfaction than a U.S. sample (Tiggeman \& Rothblum, 1988).

The degree of acculturation into U. S. society has also been found to be associated with eating problems and body 
dissatisfaction. Pumariega (1990) found that levels of disordered eating attitudes and behaviors in Hispanic adolescent girls was correlated with the degree to which a girl's family had become acculturated into American society. In addition, Abrams and her colleagues (1993) found that the prevalence of restrictive eating behaviors among African American women was associated with the degree to which the women had assimilated into mainstream culture. Such studies support Root's (1990) assertion that women of color may be generally at decreased risk when compared to EuropeanAmerican women, but individuals within these groups are subjected to the pressures of the dominant culture to varying degrees.

The above studies support the proposition that thinness worship, eating-disordered behavior, and body dissatisfaction are culturally induced phenomena, and not universal.

The role of advertising in the perpetuation of fat oppression and the pursuit of thinness

The mass media, and in particular advertisers, perpetuate and exacerbate fat oppression and body hatred YRothblum, 1994). Faludi (1991) and Wolf (1991) both argue convincingly that the advertising industry is an instrumental force in the backlash against gains women have made as a result of the feminist movement. They propose that this backlash, among other things, is designed to keep women 
preoccupied with themselves and their weight in an effort to keep them from organizing together in a fight against patriarchy. Advertisers encourage competition among women, and send the message that women should not take up space or resources either by having large-sized bodies or by consuming a lot of food (Brown, 1989). Women's contemptuousness of other women is perhaps one of the most devastating consequences of advertising (Steinem, 1994), as are feelings of inferiority, low self esteem, and passivity. Advertisers also actively reinforce and perpetuate negative stereotypes of women by depicting them in traditional roles and in positions subservient to men (Goffman, 1979; Kilbourne, 1994). Young girls and women are typically portrayed as passive, whereas young boys and men are portrayed as active (Kilbourne, 1994; Tucker, 1984). Advertisers in magazines directed toward girls, such as Seventeen, typically portray girls engaging in stereotypically "feminine" tasks such as cooking and crafts (Peirce, 1990). Moschis and Moore (1982) found that the viewing of advertisements promoted belief in traditional gender-roles in adolescents who did not previously hold such beliefs. This consequence of viewing advertisements was greatest in those families in which parents did not discuss the impact of advertising with their children; this suggests that such discussions may help to ameliorate advertising's effects. 
There are clear economic motivations to product manufacturers for keeping women dissatisfied with their bodies. Companies who wish to sell a product use advertising as the vehicle by which to deliver their messages. Advertising is a $\$ 130$ billion industry in the U.S., and has a powerful role in teaching us about the latest beauty ideals (Kilbourne, 1994). In presenting an unrealistically thin ideal of beauty for women, the advertisers, hired by cooperations, suggest that women should try to attain the ideal through dieting and the purchase of beauty products. The influence of the $\$ 30$ billion diet industry and the $\$ 20$ billion cosmetics industry as well as the $\$ 300$ million cosmetic surgery industry cannot be ignored (Kilbourne, 1994; Wolf, 1991). Advertising teaches that women's bodies are typically flawed, ugly, and in need of repair, and then offers women "solutions" to problems they did not know they had. Advertising's solutions drain women's energy and resources (Brown, 1989).

An analysis of 4,294 television commercials revealed that a message about women's attractiveness could be found in one out of every 3.8 commercials (Downs \& Harrison, 1985). Adler and Farber (1980) found that children and adults are confronted with more than 5,000 messages about attractiveness each year, nearly 2,000 of which deal directly witn beauty enhancement. Garner et al. (1980) found a significant increase in the number of diet articles in 6 
women's magazines published between 1959 and 1979. From 1959 to 1969 the mean number of weight related articles contained in the each of the 6 magazines was 17.1; from 1969 to 1979 the mean number jumped to 29.6. This increase in diet- and weight-related articles has continued. Between 1979 and 1988 the number of diet and exercise related articles in women's magazines continued to climb. Beginning in 1981, however, exercise articles became even more prevalent than diet articles (Wiseman et al., 1992). Seventeen magazine emphasizes primarily beauty and fashion. Over a period of three years, 508 of the editorial content in the magazine dealt with physical appearance (Peirce, 1990). As another 108 of the content of the magazine dealt with stereotypically "feminine" and traditional subject matter such as cooking, decorating and crafts, it can be concluded that Seventeen magazine functions to socialize teenage girls toward traditional concerns, and contributes to girls' preoccupation with physical appearance.

Exposure to advertisements containing female models has been shown to have a negative impact on how women evaluate themselves, and on the-level-of attractiveness they ascribe to other women (Irving, 1990; Richins, 1991). In addition, researchers have found support for the hypothesis that women tend to compare themselves to models (Cash, Cash, and Butters, 1980; Richins, 1991; Wood, 1989) and to attribute positive characteristics to women with thin body 
types and negative characteristics to women with heavy body types (Spillman \& Everington, 1989).

In a series of two exploratory and two experimental studies with college women, Richins (1991) found that exposure to highly attractive female models resulted in participants comparing themselves with the models, decreased satisfaction with overall physical appearance and facial beauty, and decreased ratings of the physical attractiveness of pictures of women previously rated by others as "average" in physical attractiveness. Richins also found that exposure to pictures of highly attractive female models did not alter women's ratings of their own attractiveness. Richins proposed that exposure to idealized images of beauty may have a cumulative negative effect on a woman's feelings about herself, particularly her level of satisfaction with her physical appearance.

Advertisements have also been found to impact men's perceptions of women. College-men-wo-were-interrupted while watching "Charlie's Angels" rated pictures of "average" women as less attractive than did college men who had not been watching the program (Kenrick \& Gutierres, 1980). In a follow up to that study, college men who were shown a picture of an actress/model rated pictures of "average" women as less attractive than did those men who had not seen the picture of the actress/model (Kenrick \& Gutierres, 1980). Another study by Kenrick, Gutierres, and Goldberg 
(1989) found that following exposure to pictures of unclothed women in Playboy and Penthouse magazines, men rated pictures of unclothed women who were "average" in attractiveness as less attractive than did those men who had previously been exposed to pictures of abstract art.

In addition to promoting ideals of beauty and thinness, the advertising industry plays an active role in the distortion and suppression of information. (Kilbourne, 1994; Steinem, 1994). For example, cigarettes are marketed to girls and women as a means of weight control (Kilbourne, 1994), and women's magazines that publish information about the harmful effects of smoking are threatened with a loss of advertising revenue (Steinem, 1994). In a revealing expose of the advertising industry, steinem (1994) discussed her experiences with advertisers when she was editor of Ms. magazine. Editors of women's magazines are forced to provide "supportive editorials" in praise of the products they advertise, and are restricted from printing "unfavorable commentary." For example, Steinem reported that clairol executives were outraged when she published information about the potential health consequences of using hair dyes, and subsequently, Ms. received almost no advertisements from Clairol. Steinem decided not to accept the virginia slims advertisement with the slogan "You've Come a Long Way, Baby" after a "test run" elicited numerous complaints from Ms. readers. The consequence? Phillip Morris never submitted 
another advertisement to the magazine. Because most magazines rely heavily on advertisement revenues, products are promoted not only in the labeled advertisements but also in the text of women's magazines.

The advertising industry presents consumers with images of ideal beauty that are largely unattainable. The image currently in vogue is of a young, tall, and very thin model. Despite magazine headlines that claim that "curves are back," the models depicted in advertisements are still extremely thin with breasts unusually large for their bodysize. The discrepancy in size between the "average woman" and the advertising model has continued to increase over the years.

Although feminist theorists (and others) have long believed that images of women in advertising are related to the high incidence of eating disorders and low self esteem, more empirical testing of this hypothesis is needed. In addition, the role of advertising in the perpetuation of traditional gender-role stereotypes invites further exploration into the relationships between eating-disordered behavior and gender-role stereotyping.

Psychologists have attempted to answer the questions: What causes eating disorders? Why are $90 \%$ to $95 \%$ percent of people with eating disorders women? (Wolf, 1991). Thus far, the answers provided usually deal with individual and/or familial "psychopathology." Even when socio-cultural factors 
are examined or used in theoretical analyses, they are often viewed as merely contextual factors, secondary to the "real problem." Thus, eating disorders and body hatred among women are viewed as primarily individual, rather than as social or political problems. Eating-disordered behavior is often viewed as separate and distinct from women's other behaviors in the pursuit of beauty.

Research is needed to explore more fully the relationships among eating-disordered and beauty-pursuing attitudes and behavior, attitudes consistent with genderstereotypes, and the use of unrealistically thin women models in advertising. Such research can help to shift the emphasis from a focus on the role of traditional personality or internal variables in the study of eating problems to a more political and cultural perspective that focuses on the role of fat oppression. Such a shift has clear implications for the prevention and treatment of eating problems and for the overall health and status of girls and women.

\section{Hypotheses}

This study examined the impact of exposure to women models in print advertisements on college women's attitudes toward their bodies and on their self esteem. The impact of such exposure was examined in the context of both samegender and mixed-gender viewing groups and among women who reported varying levels of eating disordered attitudes and behaviors. In addition, relationships between adherence to 
gender-stereotypes and women's attitudes and behaviors in regard to their bodies and the pursuit of beauty were explored. Finally, the present study examined eating problems in the context of women's "pursuit of beauty" and sought to provide empirical support for placing eating problems within the socio-cultural realm of women's experience.

The specific hypotheses tested are as follows:

I. Following exposure to slides of magazine advertisements that contain images of women models, a sample of college women will report lower levels of global self esteem and more negative attitudes toward their bodies than will women who are exposed to similar advertisements without images of women models.

II. Women in mixed-gender groups who view images of advertisements containing images of women models will report lower levels of global self-esteem and more negative attitudes toward their bodies than will women who view such advertisements in groups of all women. III. Prior to the experimental manipulation, measures of eating-disordered attitudes and behaviors, beauty-pursuing attitudes and behaviors, and attitudes consistent with gender-stereotypes will be positively and significantly correlated with each other and negatively and significantly correlated with measures of body-satisfaction and global self-esteem. 
IV. Women who report high levels of eating-problematic attitudes and behaviors, when compared to women who report low levels of eating-problematic attitudes and behaviors, will report more negative attitudes toward their bodies and lower levels of global self esteem following exposure to slides of advertisements containing images of women models. v. Women who report high levels of attitudes consistent with gender-stereotypes, when compared to women who report low levels of attitudes consistent with gender-stereotypes, will report more negative attitudes toward their bodies and lower levels of global self esteem following exposure to slides of advertisements containing images of women models.

VI. Men who have been exposed to slides of advertisements containing images of women models will report a preference for women who have a smaller body size than will men who have been exposed to slides of advertisements that do not contain images of women models.

METHOD

\section{Participants}

Participants included a total of 122 women and 58 men enrolled in 6 undergraduate psychology classes at the University of Rhode Island, Ringston Campus. Students earned credit in their respective classes for their voluntary participation.

Participants ranged in age from 18 to 48 , with a mean 
age of $21.79(\mathrm{SD}=6.28)$. The majority (84.18) ranged in age from 18 to 22 . In responding to questions about ethnicity, 147 (82.1\%) participants identified themselves as EuropeanAmerican, 4 (2.28) as African American, 1 (0.68) as AsianAmerican, 1 (0.6\%) as Native American or Alaskan Native, and $26(14.5 \%)$ as Other. One hundred seventy-six (98.3\%) identified as exclusively heterosexual, 2 (1.1\%) as mostly heterosexual, and $1(0.6 \%)$ as exclusively lesbian or gay. Ninety-six participants (53.6\%) described themselves as single, 64 (35.88) described themselves as "in a committed relationship," $10(5.68)$ as married, 5 (2.88) as "living with a romantic partner," and $4(2.28)$ as divorced or separated. Sixty-nine participants (38.5\%) were in their first year of college, $21(11.78)$ in their second year, 38 $(21.28)$ in their third year, 37 (20.78) in their fourth year, $8(4.5 \%)$ in graduate school, and $6(3.48)$ were nonmatriculated at the time of the study.

\section{Procedure}

Participants were recruited in two ways. For 3 classes, (Introduction to Psychology, Towards Self Understanding, and The Psychology of Social Behavior) the project was described briefly in class by the investigator or the class instructor as a 2-phase investigation of college students' perceptions of the effectiveness of advertising as related to certain personal attitudes and behaviors. Sign-up sheets were then posted in the Department of Psychology, and students were 
asked to sign up for both phases of the study prior to their participation. For phase 1, volunteers were asked to report to a classroom at the University of Rhode Island at one of four possible times to complete an initial set of questionnaires. They were asked to return for phase 2 at one of four times the following week to view slides of advertisements and evaluate their sales effectiveness. The times students' selected to participate in phase 2 determined their assignment to experimental groups. Two of the 4 times offered for phase 2 were available to women only, and 2 times were available to both women and to men. For the remaining three undergraduate psychology classes (Introduction to Psychology, Theories of Personality, and Quantitative Methods in Psychology), the investigator conducted the study during 2 class meetings, each approximately 1 week apart, with prior introduction by the course instructor. Students in two of these classes viewed advertisements that contained images of women models, and students from the remaining class viewed advertisements that did not contain images of woinen models. Students who did not want to participate were given the opportunity to leave the classroom.

All participants read an informed consent form (Appendix A); completion of survey materials constituted evidence of consent. Participants were assured of anonymity and confidentiality, instructed that they could withdraw 
from the study at any time, and informed that participation in the project would involve a total time commitment of no more than 2 hours.

Phase 1. Participants completed a set of pre-test survey questionnaires (Appendix B). The questionnaires assessed eating attitudes and behavior, beauty-pursuing attitudes and behavior, attitudes consistent with genderstereotypes, global self esteem, body satisfaction, attitudes toward one's body, perception of current bodysize, ideal body-size, and demographic information. Participants provided the last four digits of their college ID number in order to identify their responses for later matching with phase 2 responses.

Phase 2. One half of the data collection sessions included both women and men, and one-half included only women. Each group was asked to view a series of 30 advertisements presented in slide form and to evaluate each advertisement on a scale of 1 to 10 for its potential effectiveness as a sales message. Each slide was shown for 10 seconds. Group A viewed advertisements that contained images of women models, and group B viewed advertisements similar in content to those used for group $A$, but without images of women models. All advertisements were taken from women's magazines popular among college students that were published in September, 1993, October, 1993, or April, 1994; they featured such products as shoes, perfume, cosmetics, 
cigarettes, and alcohol.

After the advertising task, all participants were asked to respond again to scales that assessed global self-esteem and attitudes toward one's body (Self questionnaire, Appendix B). Participants were instructed to complete these scales by describing how they felt at that moment. They were advised that their answers might or might not differ from those they previously gave, and that the investigator was interested in responses to these items at different times.

At a debriefing session, which was conducted immediately following the second data collection session, participants were informed about the purposes and goals of the study and were also offered an opportunity to sign up for small group discussions with the investigator to further discuss issues, ideas, and concepts raised in the study. No one took advantage of the small-group discussion opportunity. Following the debriefing, participants were asked to provide anonymous feedback on the back page of their questionnaires about the two scales developed by the investigator (i.e., Beauty-Pursuing Behaviors and BeautyPursuing Attitudes), as well as about the study as a whole. At the conclusion of the data collection and debriefing, the investigator was available to discuss reactions to the study, and to provide counseling referrals to the University Counseling Center to those who requested them. (No referral was requested). 


\section{Measures}

Measures of Independent Variables. Eating Attitudes Test (EAT-26). The EAT is a 26-item self-rating questionnaire, which was developed by Garner and Garfinkel (1979). Items are presented in a forced-choice 6-point Likert scale format, where choices range from always to never. The total EAT score is then computed from the sum of all item scores. In non-clinical samples the EAT is best used to identify those with eating concerns and problematic eating patterns (Rossi \& Gibbs, 1986). Reported alpha internal consistency ranges from .79 to .94 (Garner, Olmsted, Bohr, \& Garfinkel, 1982; Raciti \& Norcross, 1987). Validity has been determined to be adequate with both anorexia nervosa and non-clinical samples (Button \& Whitehouse, 1981; Garner \& Garfinkel, 1980; Koslowsky et al., 1992; Thompson \& Schwartz, 1982). In this study, all items were used. The EAT is scored by assigning a point value of zero, one, two, or three to responses to each of the 26 items according to a scoring guide. Total scores can range from zero to 78 , with higher scores indicating more unhealthy eating attitudes and behaviors.

Bulimia Test Revised (BULIT-R). This 36-item selfreport multiple-choice scale was developed by Smith and Thelen (1984) and later was revised by Thelen, Farmer, Wonderlich, and Smith, (1991). The Bulit-R measure of bulimia is based on the criteria presented in the Diagnostic 
and Statistical Manual, third edition, revised (DSM III-R; American Psychiatric Association, 1987). Twenty-eight of the items specifically relate to the diagnosis of bulimia, and 8 un-scored items assess weight control behaviors. Scores on the 28 bulimia items are summed to provide a total score. The Bulit-R has been used with independent samples of women diagnosed with bulimia and "normal" controls, and it has a reported alpha coefficient of .97. In addition, the BULIT-R has been shown to differentiate between patients diagnosed with bulimia and "normal" control groups, and the BULIT-R is also reported to have positive and negative predictive values of .82 and higher, and a sensitivity of .62 . Testretest reliability is reported as .9. Factor analysis of the scale provided evidence for five factors: bingeing/control, radical weight-loss measures/body image, laxatives/diuretics, vomiting, and exercise. In addition, the scale has been found to be an effective screening instrument for bulimia among college-aged students (Welch, Thompson, \& Hall, 1993). In this study, all items were used. Total scores can range from 28 to 140 . Higher scores indicate more unhealthy eating attitudes and behaviors.

Beauty Pursuing Behaviors (BPB). This 35-item questionnaire was developed by the investigator in order to assess participants' non-eating and non-weight related beauty pursuing behaviors. Items were based on published theoretical writings about the pursuit of beauty in American 
culture (Freedman, 1986; Wolf, 1991). Responses, scored on a scale of 0 to 7 , yield a total score ranging from 0 to 245 . High scores indicate that the person engages in more beauty pursuing behaviors.

Beauty Pursuing Attitudes (BPA). This 20-item questionnaire was developed by the investigator in order to assess participants' endorsement of attitudes consistent with women's pursuit of beauty. Items were based on published theoretical writings about the pursuit of beauty in American culture (Freedman, 1986; Wolf, 1991). Responses, scored on a scale of 1 to 7 , yield a total score ranging from 20 to 140, after negatively worded items are reversed. High scores indicate greater endorsement of traditional attitudes pertaining to women's pursuit of beauty.

Sex Role stereotyping (SRS). This 9-item scale developed by Burt (1980) measures agreement with a variety of gender-role stereotypes. Each of the 9 items uses a 7point Likert scale ranging from strongly agree to strongly disagree: total scores can range from 9 to 63 , with high scores indicating greater degrees of gender-role stereotyping. Burt reports an alpha value of .80 and itemto-item correlations ranging from .345 to .631 . The scale's validity can be demonstrated by its positive correlations with measures of rape myth acceptance, adversarial sexual beliefs, and sexual conservatism.

Traditional Egalitarian Sex Roles (TESR). This 20-item 
Likert-type scale developed by Larsen and Long (1988), measures attitudes toward egalitarian-traditional genderroles. Part-whole correlations of items are $\geq .48$, and reported split-half reliabilities range between .85 and .91 . Validity has been demonstrated by correlations of this scale with measures of authoritarianism, religious orthodoxy and fanaticism, same-sex touching, rape acceptance, divorce, and conservatism. A varimax rotation factor analysis indicated that a single factor structure accounts for $84.6 \%$ of the variance in the scale. Scores on this scale range from 20 to 140. High scores indicate greater endorsement of traditional gender-roles.

Measures of Dependent Variables. Multidimensional Body Self Relations Questionnaire (MBSRQ). This 69-item scale, which was developed by Cash and his associates (1990) "provides a multidimensional attitudinal assessment of body image and weight related variables" (Brown, Cash, \& Mikulka, 1990). The MBSRQ consisted of three subscales: 54 items from a revised version of the Body Self Relations Questionnaire (BSRQ), 9 items on the Body Areas Satisfaction Scale, and 6 items assessing weight attitudes. The MBSRQ was systematically derived and normed from a national body image survey (Cash, Winstead, \& Janda, 1985, 1986). A factor analysis identified seven stable factors: Appearance evaluation, appearance orientation, fitness evaluation, fitness orientation, health evaluation, health orientation, 
and illness orientation (Brown et al., 1990).

In this study, 18 items which were determined to be most-relevent to this study were selected $(7$ items from the appearance evaluation factor of the BSRQ, 9 items from the Body Areas Satisfaction Scale, and 2 subjective weight appraisal items were used). Scores were summed, and could range from 18 to 105. High scores indicate more positive attitudes toward one's body and greater levels of body satisfaction.

"Rate your current level of body satisfaction on a scale of one to ten." This is a single item included by the investigator to assess participants' subjective level of body satisfaction at the time of the study. Scores can range from 1 to 10, with high scores indicating greater levels of body satisfaction.

Figure Rating Scale. This scale, developed by Fallon and Rozin (1985), is comprised of 2 sets of 9 figures, which range in size from very thin to very heavy. There is a set of female figures and a set of male figures. Participants were asked to rate the figure they believed most closely approximated their current size, their ideal size, and the figure they believed most closely approximated the size most attractive to the other gender. Men were asked to rate the female figure they believed most closely approximated the size to which they are most attracted, and women were asked to rate the male figure they believed most closely 
approximated the size to which they are most attracted. Fallon and Rozin (1985) found: "For men, the current, ideal, and most attractive figures were almost identical. For women, the current figure was heavier than the most attractive figure, which was heavier than the ideal figure" (p. 102). Scores for each item range from 1-9, with higher scores associated with heavier figures.

Rosenberg Self Esteem Scale. The Rosenberg Self Esteem Scale (Rosenberg, 1965) is a 10 item self-report measure of global self acceptance. Participants were asked to respond to both positively and negatively worded items using a fourpoint likert scale that ranged from strongly agree to strongly disagree. The scale was initially developed for use with high school students; it was normed using 5,024 high school juniors and seniors from ten randomly selected public high schools in New York State (Rosenberg, 1965). It also has been used and validated with college students and young adult volunteers (Silber \& Tippett, 1965). Test-retest reliability with college students was .85 , and the scale has been found to correlate positively with other measures of global self esteem (Robinson \& Shaver, 1973). Scores range from 10 to 40 , with high scores indicating higher levels of self esteem.

\section{RESULTS}

A total of 122 women and 58 men ( $N=180)$ participated in at least one phase of the study. For the pre-test analyses, 
102 women's surveys and 44 men's survey's were fullycompleted and usable. Seventy-six women and 30 men ( $N=106$ ) who returned for the post-test portion of the study submitted fully-completed and usable surveys. Forty-one participants submitted surveys that did not include identification numbers; where pre- and post-test data could not be matched, the data was eliminated from analyses that involved pre- and post- test data.

Hypotheses I and II.

The responses of women participants who returned completed pre- and post-test questionnaires ( $N=76)$ were analyzed using a $2 \times 2$ factorial analysis of covariance (ANCOVA). Five separate ANCOVAS were conducted with model/no model, and same gender/mixed gender group as the independent variables and post-test scores (Rosenberg's Self Esteem scale, MBSRQ, the one item body satisfaction scale, and 2 items derived from the Fallon and Rozin Figure Scale measuring perception of current body-size and ideal bodysize for self) as the dependent variables. For each ANCOVA the pre-test data that corresponded with the dependent variable was used as a co-variate. Table 1 presents the means and standard deviations of pre-test and post-test variables used in each analysis. 
Table 1. Means and standard deviations of women's scores in model/no-model and mixed-gender/single-gender conditions.

Variable

no-model

mixed-gender

single-gender

model/mixed

model/single

no-model/mixed

no-model/single

MBSRQ

model

no-model

mixed-gender

single-gender

model/mixed

model/single

no-model/mixed

no-model/single
41

35

Cell Pre-test(SD)

Size Mean

$32.88(5.04)$

$31.03(4.57)$

$32.19(4.77)$

$31.87(5.05)$

$32.60(5.11)$

$33.14(5.07)$

$31.81(4.56)$

$30.39(4.73)$

$53.05(10.56)$

$55.66(11.09)$

$54.68(9.73)$

$53.85(11.87)$

$51.40 \quad(8.43)$

$54.62(12.26)$

$58.94(10.14)$

$52.94(11.69)$
Post-test (SD)

Mean
$32.71(4.92)$

$31.49(4.83)$

$32.46(4.80)$

$31.85(5.01)$

$32.70(4.99)$

$32.71(4.98)$

$32.31(4.83)$

$30.83(4.99)$

$53.15(11.00)$

$55.97(10.39)$

$54.97(9.93)$

53.95 (11.57)

$52.65(10.16)$

53.62 (11.98)

$57.94(9.45)$

$54.33(11.41)$ 
Variable

Cell Pre-Test(SD)

Size Mean
Post-Test (SD)

Mean

Body satisfaction

\begin{tabular}{|c|c|c|c|c|c|}
\hline model & 41 & 6.24 & $(1.85)$ & 6.12 & $(1.69)$ \\
\hline no-model & 35 & 6.17 & $(2.08)$ & 6.63 & $(1.85)$ \\
\hline mixed-gender & 37 & 6.32 & $(1.72)$ & 6.46 & $(1.86)$ \\
\hline single-gender & 39 & 6.10 & $(2.16)$ & 6.26 & $(1.70)$ \\
\hline model/mixed & 20 & 6.15 & $(1.63)$ & 6.20 & $(1.85)$ \\
\hline model/single & 21 & 6.33 & $(2.08)$ & 6.05 & $(1.56)$ \\
\hline no-model/mixed & 16 & 6.69 & $(1.78)$ & 6.75 & $(1.95)$ \\
\hline no-model/single & 18 & 5.83 & $(2.28)$ & 6.50 & $(1.86)$ \\
\hline \multicolumn{6}{|l|}{ Self-figure } \\
\hline model & 41 & 3.98 & $(1.23)$ & $4 \cdot 10$ & $(1.06)$ \\
\hline no-model & 35 & 3.69 & $(1.08)$ & 3.63 & $(1.06)$ \\
\hline mixed-gender & 37 & 3.81 & $(1.05)$ & 3.86 & $(1.06)$ \\
\hline single-gender & 39 & 3.87 & $(1.28)$ & 3.90 & $(1.23)$ \\
\hline model/mixed & 20 & 4.00 & $(.97)$ & 4.10 & $(.97)$ \\
\hline model/single & 21 & 3.95 & $(1.47)$ & $4 \cdot 10$ & $(1.37)$ \\
\hline no-model/mixed & 16 & 3.62 & $(1.15)$ & 3.62 & $(1.15)$ \\
\hline no-model/single & 18 & 3.78 & $(1.06)$ & 3.67 & $(1.03)$ \\
\hline
\end{tabular}


Variable

Cell Pre-Test (SD)

Post-Test (SD)

Size Mean

Mean

Ideal figure

$\begin{array}{llllll}\text { model } & 41 & 2.93 & (.61) & 2.98 & (.65) \\ \text { no-model } & 34 & 2.71 & .76) & 2.74 & (.86) \\ \text { mixed-gender } & 36 & 2.75 & (.69) & 2.78 & (.80) \\ \text { single-gender } & 39 & 2.90 & (.68) & 2.95 & (.72) \\ \text { model/mixed } & 20 & 2.85 & (.59) & 2.90 & (.64) \\ \text { model/single } & 21 & 3.00 & (.63) & 3.05 & (.67) \\ \text { no-model/mixed } & 16 & 2.62 & (.81) & 2.62 & (.96) \\ \text { no-model/single } & 18 & 2.78 & (.73) & 2.83 & (.79)\end{array}$

Self-Perception. When pre-test figure-ratings of women's perceptions of their own body-size were used as covariates, there was a significant difference in the adjusted post-test figure-ratings of women's perceptions of their own body-size between women who saw advertisements with or without female models $(\underline{F}(1,75)=4.32, \underline{p}<.05)$. Those women who saw advertisements that depicted models viewed themselves as having larger-sized bodies (LS mean=3.98, $\mathrm{SE}=.07$ ) than did those women who saw advertisements that did not depict models (IS mean=3.77, $\mathrm{SE}=.07$ ). There were no significant differences in self perception of body size between women who viewed advertisements in mixed-gender (LS mean=3.86, $\mathrm{SE}=.07$ ) or single-gender groups (LS mean $=3.90, \mathrm{SE}=.07$ ) 
$(\underline{F}(1,75)=.07, \underline{p}>.05)$. The interaction effect did not reach significance $(\underline{F}(1,75)=.43, \underline{p}>.05)$.

Ideal body-size. When pre-test figure ratings of women's "ideal body-size" were used as co-variates, there were no significant differences in the adjusted post-test figure ratings of women's "ideal body-size" between women who saw advertisements that depicted models (LS mean=2.88, $\mathrm{SE}=.07$ ) or did not depict models (LS mean=2.84, $\mathrm{SE}=.07$ ) $(\underline{F}(1,74)=.15, \underline{p}>.05)$. There were no significant differences between women who viewed advertisements in mixed-gender (LS mean=2.84, $\mathrm{SE}=.07$ ) or single-gender groups (LS mean=2.88, $\mathrm{SE}=.07) \quad(\underline{F}(1,74)=.15, \underline{p}>.05)$. Nor was there a significant interaction effect $(\underline{F}(1,74)=.09, \underline{p}>.05)$.

Self Esteem. When pre-test self-esteem scores were used as co-variates, there were no significant differences in the adjusted post-test global self-esteem scores between women who saw advertisements that depicted models (LS mean=31.98, $\mathrm{SE}=.40$ ) or did not depict models (LS mean=32.35, $\mathrm{SE}=.44$ ) $(\underline{F}(1,75)=.39, \underline{p}>.05)$. There were no significant differences between women who viewed advertisements in mixed-gender (LS mean=32.32, $\mathrm{SE}=.42$ ) or single-gender groups (LS mean=32.00, $\mathrm{SE}=.41) \quad(\underline{F}(1,75)=2.04, \underline{p}>.05)$. The interaction effect did not reach significance $(\underline{F}(1,75)=.83, \underline{p}>.05)$.

MBSRQ. When pre-test MBSRQ scores were used as covariates, there were no significant differences in the adjusted post-test MBSRQ scores between women who saw 
advertisements that depicted models (LS mean=54.28, $\mathrm{SE}=.69$ ) or did not depict models (LS mean=54.65, $\mathrm{SE}=.75$ ) $(\underline{F}(1,75)=.13, \underline{p}>.05)$. There were no significant differences between women who viewed advertisements in mixed-gender (LS mean=54.52, $\mathrm{SE}=.73$ ) or single-gender groups (LS mean=54.41, $\mathrm{SE}=.71)(\underline{F}(1,75)=.01, \underline{p}>.05)$. The interaction effect did not reach significance $(\underline{F}(1,75)=3.26, \underline{p}>.05)$.

Single item body-satisfaction. When pre-test bodysatisfaction scores were used as co-variates, there were no significant differences in the adjusted post-test bodysatisfaction scores between women who saw advertisements that depicted models (LS mean=6.12, $\mathrm{SE}=.23$ ) or did not depict models (LS mean=6.63, SE $=.25)(\underline{F}(1,75)=.11, \underline{p}>.05)$. There were no significant differences between women who viewed advertisements in mixed-gender (LS mean=6.46, SE=.24) or single-gender groups (LS mean=6.26, $S E=.24)(\underline{F}(1,75)=.05$, p>.05). The interaction effect did not reach significance. $(\underline{E}(1,75)=.24, \underline{p}>.05)$.

Hypothesis III.

Correlational analyses were conducted for women $(\mathrm{N}=102)$ and men ( $N=44)$ separatedly using pre-test scores on each measure (EDI, BULIT, BPB, BPA, SRS, and TESR, MBSRQ, single item body satisfaction, 2 items from the figure rating scale and Rosenberg's self esteem measure). These correlations are shown in Table $2 \mathrm{a}$ for women and Table $2 \mathrm{~b}$ for men. 


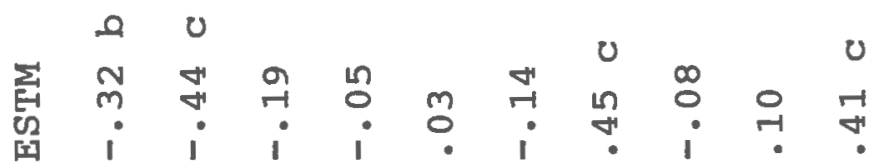

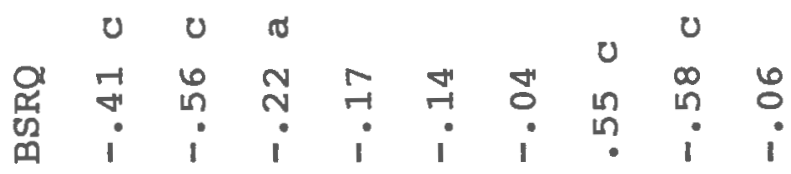

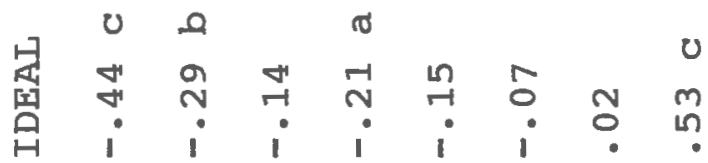

곅

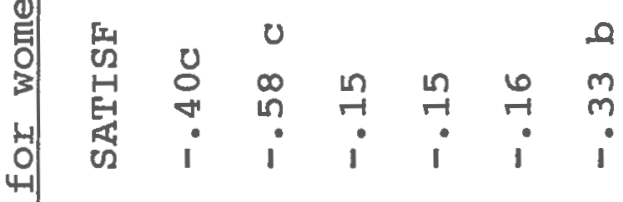

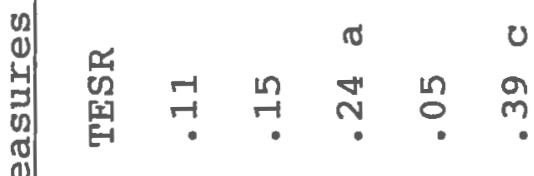

离

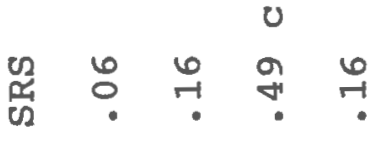

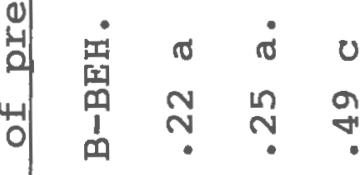

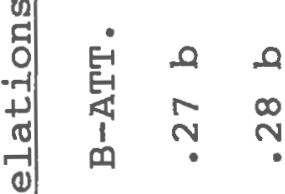

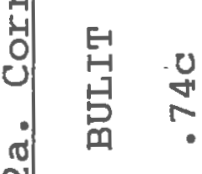

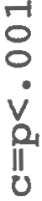

$\ddot{-1}$
0
$ن$
0
0

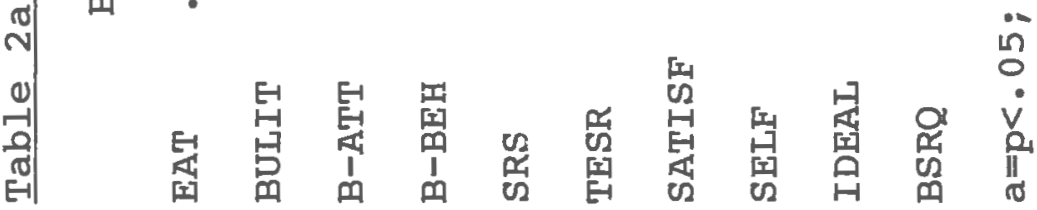




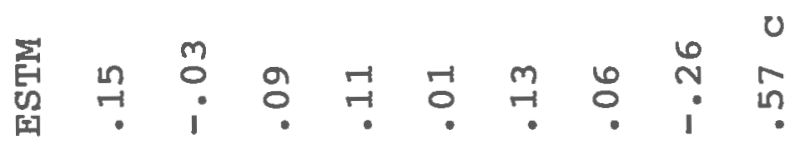

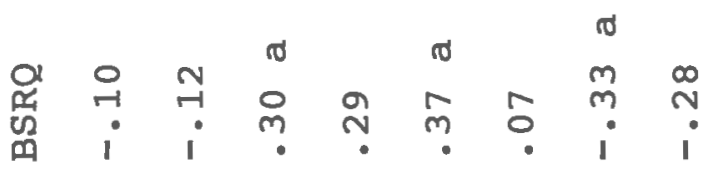

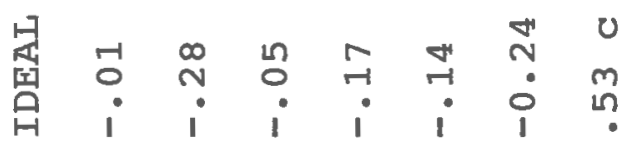

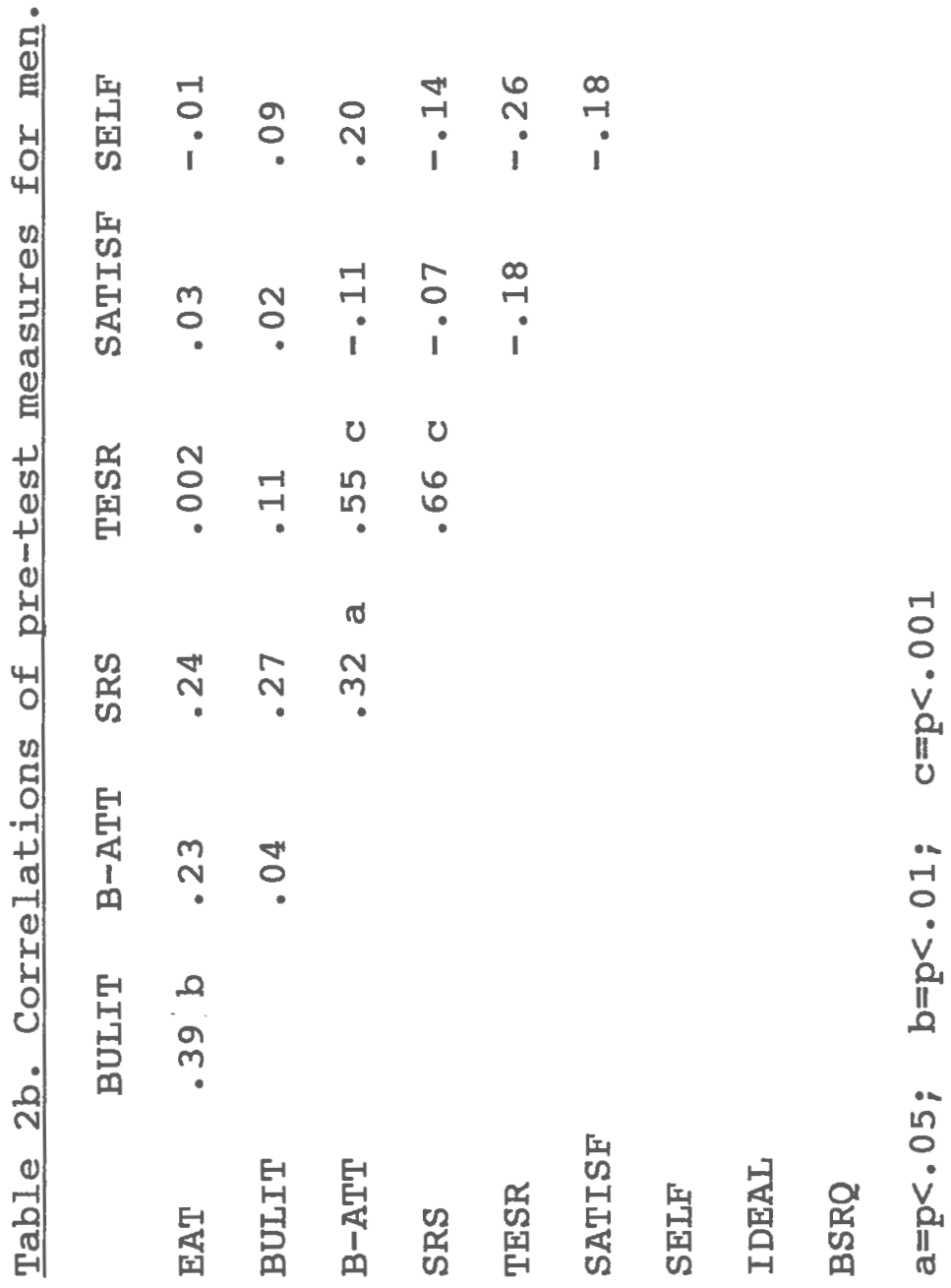


Women's correlations. For women, the two measures of eating-disordered attitudes and behaviors, the EAT and BULIT, were significantly and positively correlated with each other $(r=.74)$, with beauty-attitudes (EAT: $r=.27$; BULIT: $r=.28$ ), and beauty-behaviors (EAT: $r=.22$; BULIT: $r=.25$ ), and were significantly and negatively correlated with body-satisfaction (EAT: $r=-.40$; BULIT: $r=-.58$ ), MBSRQ (EAT $r=-.41$; BULIT: $r=-.56$ ), global self-esteem (EAT: r=.44; BULIT: r=-.44), and ratings of ideal body-size (EAT: $r=-.44$; BULIT: $r=-.29$ ) .

Beauty-attitudes and beauty-behaviors were significantly and positively correlated with each other $(r=.49)$. Beauty-attitudes were also significantly and positively correlated with SRS $(r=.49)$ and TESR $(r=.24)$, and significantly and negatively correlated with MBSRQ ( $r=-$ .22). Beauty-behaviors were significantly and negatively correlated with ratings of ideal body-size ( $r=-.21)$.

The two measures of sex-role steretyping (SRS) and endorsement of traditional gender-roles (TESR) were significantly and positively correlated with each other $(r=.39)$, and the TESR was also significantly and negatively correlated with body satisfaction $(r=-.33)$.

The two measures of attitudes toward the body (MBSRQ and the single-item body satisfaction score) were significantly and positively correlated with each other $(r=.55)$ and with global self-esteem (MBSRQ: $r=.45$; body 
satisfaction: $r=.45$ ). The MBSRQ was also significantly and negatively correlated with figure-ratings of current bodysize $(r=-.58)$.

Figure ratings of current body-size were also positively and significantly correlated with ratings of ideal body-size $(r=.53)$.

Men's correlations. Measures of eating-disordered attitudes and behaviors (EAT and BULIT) were significantly and positively correlated with each other $(r=.39)$.

The measure of beauty attitudes was significantly and positively correlated with SRS $(r=.32)$, and the BSRQ $(r=.30)$.

Measures of sex-role stereotyping (SRS) and endorsement of tradition gender-roles (TESR) were positively and significantly correlated with each other $(r=.66)$.

Figure-ratings of men's own body-size were significantly and positively correlated with ideal body-size $(r=.53)$, and significantly and negatively correlated with the MBSRQ $(r=-.33)$.

Global self-esteem was significantly and positively correlated with the MBSRQ $(r=.57)$.

Hypotheses IV, and V.

Combining of independent variables. Women's responses to four of the continuous independent variables (EAT, BULIT, SRS, and TESR) were combined to form two discrete 
independent variables: Eating Problems and Gender Stereotyping .

The eating-problems variable was defined as the sum of scores on the EAT and BULIT; total scores ranged from 29 to 185, with a mean of $73.15(S D=32.06)$. Higher scores indicated higher levels of eating problems. Participants were labelled as either "high eating problems" or "low eating problems" based on a median split (median=65). Fiftytwo women were designated as "high eating problems" with a mean EAT score of $23.31(S D=12.05)$ and a mean BULIT score of $73.40(\mathrm{SD}=20.01)$. Fifty women were designated as "low eating problems" with a mean EAT score of $6.62(\mathrm{SD}=4.45)$ and a mean BULIT score of $42.02(\mathrm{SD}=6.98)$.

The gender-stereotyping variable was defined as the sum of scores on the Sex Role Stereotyping and Traditional Egalitarian Sex Roles scales; total scores ranged from 29 to 110, with a mean of $60.00(S D=14.92)$. Higher scores indicated a greater adherence to gender stereotypes and greater endorsement of traditional gender-roles. Fifty-one participants were designated as "high stereotyping" (mean $\mathrm{SRS}=28.59, \mathrm{SD}=6.13$; mean $\mathrm{TESR}=43.55, \mathrm{SD}=8.50$ ) and 51 as "low gender-stereotyping" (mean SRS=19.20, SD=5.03; mean TESR=28.67, SD=5.97) based on a median split (median=57.5) . The responses of women participants who were exposed to advertisements containing images of women models $(N=41)$ were analyzed using $2 \times 2$ factorial analysis of co-variance 
(ANCOVA). Five separate ANCOVAS were conducted using high vs. low eating problems and high vs. low gender stereotyping as the independent variables, and the post-test data (Rosenberg's self esteem measure, MBSRQ, single item body satisfaction, and 2 items from the figure rating scale measuring perception of current body-size and ideal bodysize for self) as dependent measures. For each ANCOVA, the corresponding pre-test measure of the dependent variable was used as a co-variate. See Table 3 for the means and standard deviations of the pre-test and post-test measures used in each analysis. 
Table 3. Means and standard deviations of women's scores in high-eating/low eating and high-stereotyping/lowstereotyping conditions.

Variable

22

high-stereo

17

low-stereo

24

hi-eat/hi-stereo 7

hi-eat/lo-stereo 12

lo-eat/hi-stereo 10

lo-eat/lo-stereo

12

MBSRQ

high-eating

19

low-eating

high-stereo

low-stereo

hi-eat/hi-stereo 7

hi-eat/lo-stereo 12

lo-eat/hi-stereo 10

lo-eat/lo-stereo
Pre-test (SD)

Mean

$31.37(5.35)$

$34.18(4.47)$

$31.65(5.22)$

$33.75(4.82)$

$29.00(5.07)$

$32.75(5.21)$

$33.50(4.70)$

$43.75(4.39)$

$46.26(9.54)$

$58.91(7.54)$

$52.71(12.60)$

$53.29(9.13)$

$43.29(12.13)$

$48.00 \quad(7.73)$

$59.30(8.18)$

$58.58(7.32)$
Post-test (SD)

Mean

$$
\begin{array}{ll}
31.00 & (4.87) \\
34.18 & (4.50) \\
31.06 & (4.87) \\
33.88 & (4.71) \\
27.71 & (3.73) \\
32.92 & (4.64) \\
33.40 & (4.25) \\
34.83 & (4.78)
\end{array}
$$

$$
46.58(10.02)
$$$$
58.82(8.47)
$$$$
51.35 \text { (13.50) }
$$$$
54.42(8.92)
$$$$
40.71 \text { (11.50) }
$$$$
50.00(7.59)
$$$$
58.80(9.28)
$$

$58.83(8.14)$ 
Variable

19

high-eating

low-eating

high-stereo

low-stereo

hi-eat/hi-stereo

hi-eat/lo-stereo

lo-eat/hi-stereo

lo-eat/lo-stereo

12

Self figure

high-eating

low-eating

high-stereo

low-stereo

hi-eat/hi-stereo

hi-eat/lo-stereo

lo-eat/hi-stereo 10

lo-eat/lo-stereo
12

19

22

17

24

7

12
Cell Pre-test(SD)

Size Mean
Post-test (SD)

Mean
$5.47(1.90)$
$6.68(1.29)$
$5.76(2.11)$
$6.38(1.31)$
$4.14(1.95)$
$6.25(1.42)$
$6.90(1.37)$
$6.50(1.24)$

$7.08 \quad(1.24)$
$5.32(2.00)$

7.05 (1.29)

$5.94(2.19)$

$6.46(1.59)$

$4.43(2.30)$

$5.83(1.70)$

7.00 (1.41)

9

4.42 (1.39)

$3.59(.96)$

3.82 (1.55)

$4.08(.97)$

$4.71(1.80)$

4.25 (1.14)

$3.20(1.03)$

$3.92(.79)$
$4.42(1.26)$

$3.82(1.05)$

3.88 (1.54)

$4.25(.85)$

4.57 (1.81)

$4.33(.89)$

$3.40(1.17)$

$4.17(.83)$ 
Variable

Cell Pre-test(SD)

Post-test (SD)

Size Mean

Mean

Ideal figure

$\begin{array}{lllll}\text { high-eating } & 19 & 2.89(.66) & 2.74(.65) \\ \text { low-eating } & 22 & 2.95(.57) & 3.18(.59) \\ \text { high-stereo } & 17 & 2.94(.66) & 2.88(.60) \\ \text { low-stereo } & 24 & 2.92(.58) & 3.04(.69) \\ \text { hi-eat/hi-stereo } & 7 & 3.14(.69) & 2.71(.76) \\ \text { hi-eat/lo-stereo } & 12 & 2.75(.62) & 2.75(.62) \\ \text { lo-eat/hi-stereo } & 10 & 2.80(.63) & 3.00(.47) \\ \text { lo-eat/lo-stereo } & 12 & 3.08(.51) & 3.33(.65)\end{array}$

MBSRQ. When women's pre-test MBSRQ scores were used as co-variates, there was a significant difference in the adjusted post-test MBSRQ scores between women who were classified as "high gender-stereotyping" and "low genderstereotyping" $(\underline{F}=(1,40) 4.23, \underline{p}<.05)$. Those women who were classified as "high stereotyping had lower MBSRQ scores (LS mean=51.36, $\mathrm{SE}=1.06$ ) than those women classified as "low stereotyping" (LS mean=54.20, $\mathrm{SE}=.87$ ). There were no significant differences in MBSRQ scores between women who were classified as "high eating problems" (IS mean=52.11, $\mathrm{SE}=1.18$ ) and women classified as "low eating problems" (LS mean=53.44, $\mathrm{SE}=1.04) \quad(\underline{F}(1,40)=.45, \underline{p}>.05)$. The interaction between EATING and STEREOTYPING did not reach significance $(\underline{F}(1,40)=2.40, p>.05)$.

Women's body-satisfaction. When women's pre-test body48 
satisfaction scores were used as co-variates, there were no significant differences in the adjusted post-test bodysatisfaction scores between women who were classified as "high stereotyping" (LS mean=5.85, SE=.27) and "low stereotyping" (LS mean=6.24, $\mathrm{SE}=.22)(\underline{F}(1,40)=1.24, \underline{p}>.05)$. There were no significant differences in body satisfactionscores between women who were classified as "high eating problems" (LS mean=5.89, $\mathrm{SE}=.28$ ) and women classified as "low eating problems" (LS mean=6.20, $\mathrm{SE}=.24) \quad(\mathrm{E}(1,40)=1.24$, p>.05). The interaction between EATING and STEREOTYPING was significant $(\underline{F}(1,40)=5.88, \underline{p}<.05)$. Women who were classified as "high eating problems" and "high gender-stereotyping" had lower body-satisfaction scores (LS mean=5.28, $\mathrm{SE}=.45$ ) than than women classified as "high eating problems" and "low gender-stereotyping" (LS mean=6.51, SE=.31).

Ideal body-size. When women's pre-test figure ratings of their ideal body-size were used as co-variates, there was a significant difference in the adjusted figure ratings of women's ideal body-size between women who were classified as "high eating problems" and "low eating problems" (E( 1 , 40)=10.06, $\mathrm{p}<.05$ ). Women who were classified as "high eating-problems had a smaller-sized ideal body (IS mean=2.72, $\mathrm{SE}=.10$ ) than women classified as "low eating problems: (LS mean=3.16, SE=.09). There were no significant differences in women's ideal body-size between women rated as "high gender-stereotyping" (LS mean=2.82, $\mathrm{SE}=.11$ ) and 
"low gender-stereotyping (LS mean=3.05, $\mathrm{SE}=.09$ )

$(\underline{F}(1,40)=2.66, p>.05)$. The interaction between EATING and STEREOTYPING did not reach significance $(\underline{F}(1,40)=.53$, p>.05).

Self-perception. When women's pre-test figure ratings of their perception of their own body-size were used as covariates, there were no significant differences in the adjusted figure ratings of women's perception of their own body-size between women who were classified as "high eating problems" (IS mean=3.99, SE=.11) and "low eating problems" (IS mean=4.16, $\mathrm{SE}=.10)(\underline{F}(1,40)=1.19, \mathrm{p}>.05)$, or between women who were classified as "high gender-stereotyping" (IS mean=4.00, SE=.11) and women classified as "low genderstereotyping" (LS mean=4.15, $\mathrm{SE}=.09)(\underline{E}(1,40)=1.10, p>.05)$. The interaction between EATING and STEREOTYPING did not reach significance $(\underline{F}(1,40)=.05, \underline{p}>.05)$.

Self-esteem. When women's pre-test self-esteem scores were used as co-variates, there were no significant differences in the adjusted post-test global self-esteem scores between women classified as "high eating problems" (IS mean=31.00, SE=4.95) and "low eating problems" (LS mean=34.18, $\mathrm{SE}=4.50) \quad(\underline{F}(1,40)=2.49, \underline{p}>.05)$, or between women who were classified as "high gender-stereotyping" (IS mean=31.06, $\mathrm{SE}=4.87$ ) and women classified as "low genderstereotyping" (LS mean=33.88, $\mathrm{SE}=4.71)(\underline{F}(1,40)=3.13$, p>.05). The interaction between EATING and STEREOTYPING did 
not reach significance $(\underline{F}(1,40)=1.48, \underline{p}>.05)$.

Hypothesis VI.

The responses of men participants who returned completed pre- and post-test questionnaires ( $N=27)$ were analyzed using analysis of covariance (ANCOVA). A single ANCOVA was conducted using the experimental condition of model/no-model as the independent variable and 1 item from the figure rating scale measuring ideal body-size for women as the dependent variable. The pre-test data corresponding to the dependent variable was used as a co-variate. Table 4 shows the means and standard deviations of men's pre-test and post-test scores.

Table 4. Means and standard deviations of men's scores in model/no-model condition.

Variable

Cell Pre-test Post-test (SD) Size Mean Mean

Ideal woman
model
15
$3.60(1.59)$
$3.40(.51)$
no-model
12
$3.33(.49)$
$3.08(.29)$

Ideal body-size for women. When pre-test figure ratings of men's "ideal woman" were used as co-variates, there were no differences in the adjusted post-test figure ratings of 
men's "ideal woman" between men who saw advertisements that depicted models (LS mean=3.38, SE=.09) or did not depict models (LS mean=3.11, $\mathrm{SE}=.11)(\underline{\mathrm{F}}(1,26)=3.52, \mathrm{p}>.05)$.

Gender comparisons.

Women's $(\mathrm{N}=102)$ and men's $(\mathrm{N}=44)$ pre-test responses were compared with each other using analysis of variance (ANOVA) and multiple analysis of variance (MANOVA). Two separate ANOVAS were conducted using gender as the independent variable, and pre-test measures of self-esteem and beauty attitudes as dependent variables. Four separate MANOVAS were conducted using 1 . body image measures (MBSRQ and the single-item body-satisfaction), 2. genderstereotyping measures (SRS and TESR), 3. eating attitudes and behavioral measures (EAT and BULIT), and 4. figure ratings $(2$ items measuring perception of current body-size, ideal body-size) as the dependent variables. Table 5 presents the means and standard deviations of the variables used in each analysis. 
Table 5. Women and men's means and standard deviations on pre-test measures

\begin{tabular}{llllll} 
Variable & \multicolumn{2}{l}{ Cell Women's (SD) } & \multicolumn{2}{l}{ Cell Men's(SD) } \\
& Size Mean & \multicolumn{2}{l}{ Size Mean } \\
Self-esteem & 102 & $32.03(4.92)$ & 44 & $33.61(5.33)$ \\
MBSRQ & 102 & 53.30 & $(10.89)$ & 44 & $61.20(9.94)$ \\
Body Satisfaction & 102 & 6.08 & $(2.03)$ & 44 & $6.61(2.30)$ \\
SRS & 102 & 23.89 & $(7.31)$ & 44 & $29.91(9.23)$ \\
TESR & 102 & 36.11 & $(10.46)$ & 44 & $58.50(20.52)$ \\
EAT & 102 & 15.13 & $(4.21)$ & 44 & $4.21(3.62)$ \\
BULIT & 102 & 58.02 & $(21.78)$ & 44 & $46.13(10.80)$ \\
Beauty-Attitudes & 102 & $83.13(14.45)$ & 44 & $89.77(11.80)$ \\
Self-figure & 101 & 3.86 & $(1.49)$ & 44 & $4.27(1.28)$ \\
Ideal figure & 101 & 2.76 & $(.67)$ & 44 & $4.34(1.08)$
\end{tabular}

MBSRQ and body satisfaction. The overall MANOVA using pre-test MBSRQ scores and the single-item body-satisfaction scores as dependent variables and gender as the independent variable was significant $(\underline{E}(2,143)=8.48, \underline{p}<.05)$. Follow-up ANOVAS indicated that women's pre-test MBSRQ scores (mean=53.30, $S D=10.90$ ) were lower than men's pre-test MBSRQ scores (mean=61.20, $\mathrm{SD}=9.9) \quad(\underline{E}(1,145)=17.02, \underline{\mathrm{p}}<.05)$. There were no significant differences between the pre-test level of body satisfaction of women (mean $=6.08, \mathrm{SD}=2.03$ ) and men (mean=6.61, $\mathrm{SD}=2.30) \quad(\underline{F}(1,145)=1.96, \underline{p}>.05)$.

SRS and TESR. The overall MANOVA using pre-test SRS and 
TESR scores as dependent variables and gender as the independent variable was significant $(\underline{F}(2,143)=37.87$, $\underline{p}<.05)$. Follow-up ANOVAS indicated that the women's pre-test SRS scores (mean=23.89, $\mathrm{SD}=7.30$ ) were significantly lower than men's pre-test SRS scores (mean=29.91 SD=9.22) $(\underline{F}=(1,145)=17.72, \underline{p}<.05)$. Women's pre-test TESR scores (mean=36.11, SD=10.16) were significantly lower than men's pre-test TESR scores (mean=58.50, $S D=20.52)(\underline{F}(1,145)=76.13$, $\mathrm{p}<.05)$.

EAT and BULIT. The overall MANOVA using pre-test EAT and BULIT scores as dependent variables and gender as the independent variable was significant $(\underline{F}(2,143)=16.89$, $\mathrm{p}<.05)$. Follow-up ANOVAS indicated that the women's pre-test EAT scores (mean=15.13, $S D=12.38$ ) were significantly higher than men's pre-test EAT scores (mean=4.21 SD=3.62) $(\underline{F}(1,145)=32.92, \mathrm{p}<.05)$. Women's pre-test BULIT scores (mean=58.02, $\mathrm{SD}=21.78$ ) were significantly higher than men's pre-test BULIT scores (mean=46.13, $S D=10.80$ ) $(\underline{F}(1,145)=11.81, \underline{p}<.05)$.

Fiqure ratings. The overall MANOVA using pre-test figure ratings measuring current body-size and ideal bodysize as dependent variables and gender as the independent variable was significant $(\underline{F}(2,142)=66.69, \underline{p}<.05)$.

Follow-up ANOVAS indicated that the women's pre-test ideal body-size for self (mean=2.76, $\mathrm{SD}=.67$ ) was significantly smaller than men's pre-test ideal body-size 
for self (mean=4.34 SD=1.08) $(\underline{F}(1,144)=115.95, \underline{p}<.05)$.

There were no significant differences between women's pre-test perception of their own body-size on the women's figures (mean=3.86, $\mathrm{SD}=1.15$ ) and men's pre-test perception of their own body-size on the men's figures (mean=4.27, $S D=1.28) \quad(\underline{F}(1,144)=3.66, p>.05)$.

Beauty attitudes. Analysis of variance indicated that women's pre-test scores of attitudes about women's beauty (mean=83.13 $\mathrm{SD}=14.45$ ) were significantly lower than men's pre-test scores of attitudes about women's beauty $($ mean=89.77, $\mathrm{SD}=11.80) \quad(\underline{F}(1,145)=7.20, \underline{\underline{p}}<.05)$.

Self-esteem. Analysis of variance indicated that women's pre-test global self-esteem scores (mean=32.03, $\mathrm{SD}=4.92$ ) were not significantly different from men's pretest global self-esteem scores (mean=33.61, $\mathrm{SD}=5.33$ ) $(\underline{F}(1,145)=3.01, \underline{p}>.05)$.

Pursuit of beauty questionnaire.

Items from the Pursuit of Beauty Questionnaire (comprised of the Beauty Pursuing Behaviors and Beauty Pursuing Attitudes scales) were combined after 6 items were reverse coded so that all items were uni-directional (items $39,41,42,44,45,53)$.

Cronbach's alpha on all 55 items was 0.87 , and the elimination of any single item did not significantly alter the alpha level. 
Factor analysis with varimax rotation was performed on women's responses to the 55 items. Principle componants analysis was used prior to factor analysis to estimate number of factors. Three factors were extracted, and together accounted for $28.42 \%$ of the variance. Factor 1 accounted for $11.13 \%$ of the variance; factor 2 accounted for 10.958 of the variance; and factor 3 accounted for 6.368 of the variance. When items with loadings less than or equal to . 30 (10 items) or loadings greater than .30 on more than one factor ( 6 items) are eliminated, 16 items were retained on factor 1, 16 items on factor 2, and 7 items on factor 3, for a total of 39 items, or 718 of the original items. See Table 6 for a listing of item content and loading for each item that has a loading $\geq .30$ on only 1 factor. 
Table 6. Beauty questionnaire items and factor loadings for retained items.

Item number and content Factor Factor Factor 1 2 3

23. Shaving bikini area .69

25. Shaving upper-legs .65

20. Using fingernail polish .61

22. Shaving underarms $\quad .61$

24. Shaving lower-legs $\quad .59$

29. Getting a manicure .58

21. Using toenail polish .58

10. Using lipstick .56

19. Wearing perfume .51

31. Getting a facial .47

28. Removing eyebrow-hair .41

27. Removing lip-hair .40

13. Using lipliner .37

4. Breast-enlargement .34

26. Removing stomach-hair .32

15. Wearing mascara .31

49. Should exercise for $\quad .72$

weight-control

50. Should spend money for .71

beauty treatments

51. Should read fashion magazines 
Item number and content

55. Should dress femininely

36. Should do all to try to improve looks

38. Should shave legs

37. Should wear cosmetics

48. Should exercise for weight-control

47. Dieting for weight-loss is a good idea

46. Thin women are more attractive than fat women

52. Should shave underarms

41. Physical attractiveness to others is important

42. Should choose clothes

for fashion, not comfort

18. Uses blush

44. Should try to look like

a fashion model

53. Should let partner see

.55

.53

.53

.50

.48

.46

.44

.40

.31
Factor Factor Factor

1

2 you when not at "best"

7. Facelift

.83

2. Eyelid Surgery 
Item number and content Factor Factor Factor 1 2 3

6. Retin A for wrinkles .65

5. Collagen injections .55

33. Uses hair color .35

3. Rhinoplasty (nose-job) .35

34.Straightens or perms hair

Factor I can be described as "Common Beauty Behaviors". All items loading on this factor are behavioral, and include fairly common beauty procedures. The only potentially uncommon beauty procedure listed on factor 1 is breast enlargement, and this item may be eliminated on future versions of the scale.

Factor 2 can be described as "Attitudes about Women's Beauty Rituals". Fifteen of the 16 items loading on this factor are attitudinal measures about beauty. Items all load in a direction consistent with traditional views about feminine beauty. Only one item, the frequency of using blush, is not an attitudinal measure, and will likely be eliminated on future versions of the scale.

Factor 3 can be generally described as "Uncommon or Expensive Beauty Behaviors". The majority of items loading on this factor ( 5 of 7 ) are about the likelihood of having expensive cosmetic surgery procedures. These procedures, such as eyelid surgery and Retin-A for wrinkles, are more 
likely to be considered by older women, and although many college women may have considered rhinoplasty, its cost is likely to be prohibitive. The other two items both concern expensive hair-treatments, that although not uncommon among college students, may be prohibitively expensive for women on a student's income. It is likely that these items will be discarded on future versions of the scale, leaving a "cosmetic surgery" factor.

All data were analyzed using the SAS statistical package, with the exception of the calculation of Cronbach's alpha for the Beauty Questionnaire, which was performed using the SPSS statistical package. For those scales with few missing items, the individual's mean score was substituted for the missing data point so that total sums would remain fair indicators of a person's score. Responses of participants who left entire scales blank were eliminated from the relevant analyses.

\section{DISCUSSION}

The hypothesis that viewing advertisements that depicted attractive female models would impact negatively on women's attitudes toward their bodies and their global selfesteem was only partially supported in this study. Women who saw advertisements with models, when compared with women who saw advertisements without models, did subsequently perceive their own body-size to be heavier. These results suggest 
that women do compare their body-size to the body-size of models, and they see themselves as heavier as a result of that comparison.

Women who were and were not exposed to images of attractive female models did not subsequently differ on measures of global self-esteem, attitudes toward their bodies, body-satisfaction, or figure ratings of ideal bodysize. Men's ratings of ideal women's bodies also did not differ in the model and no-model conditions.

The effects of viewing models in this study are not consistent with prior research that has found that even brief exposure to highly attractive female models impacts standards of women's physical attractiveness and women's level of body-satisfaction (Kenrick \& Gutierres, 1980; Kenrick et al., 1989; Richins, 1991). Because college students are bombarded with images of highly-attractive models, perhaps such a brief exposure in a laboratory setting was not sufficient to alter attitudes further, even temporarily.

The hypothesis that women who viewed models in advertisements in mixed-gender groups would have more negative attitudes toward their bodies and lower self-esteem than those in single-gender viewing groups was not supported in this study. Women who viewed models in single-gender vs. mixed-gender groups did not differ in subsequent measures of attitudes toward their bodies, body-satisfaction, and global 
self-esteem scores, or in their figure-ratings of current and ideal body-size.

Given that college women in particular are known to have highly negative views of their bodies in general, the condition of being in a single- or mixed-gender group for such a brief amount of time was not sufficient to alter preexisting negative attitudes, feelings, and beliefs. However, there is evidence that being in the company of men over a longer period of time does alter women's attitudes toward themselves. For example, Berg (1988) found a greater incidence of bulimic symptoms, body-dissatisfaction, drive for thinness, and self-induced vomiting in women living on co-educational vs. single-sex floors of a college dormitory. And Rodin et al. (1984) reported that schools with an emphasis on dating also have a higher prevalence of weight concerns.

In addition, lesbians have been found to have a lower incidence of dieting and weight concerns than heterosexual women (Brand, Rothblum, Solomon, 1992), although Dworkin (1989) has pointed out that lesbians report high levels of body dissatisfaction and that they discriminate against fat women. However, individuals who want to be physically appealing to men may be at greater risk for the development of eating disorders than those who want to be physically appealing to women, as is suggested by the finding that gay men have a higher incidence of weight concerns than do 
heterosexual men (Brand et al., 1992; Gettleman \& Thompson, 1993).

The hypothesis that women with high, as compared to low, levels of eating-disordered attitudes and behaviors and high, as compared to low, levels of adherence to gender stereotypes would differ on measures of body attitudes and self-esteem following exposure to images of attractive female models were partially supported by this study . Following exposure to advertisements that depicted models, women with attitudes and behaviors more consistent with eating disorders subsequently reported a thinner ideal bodysize than women whose attitudes and behaviors were less consistent with eating disorders. Women with greater levels of adherence to gender stereotypes had more negative attitudes about their bodies than women who adhered less to gender-stereotypes, and among those women whose attitudes and behaviors were most consistent with eating disorders, those with greater endorsement of gender stereotypes reported less satisfaction with their bodies.

These results suggest that those women who report greater levels of eating-disordered attitudes and behaviors, and those women who hold more traditional and stereotypical views about women's and men's relationships, may be the most vulnerable to the impact of viewing attractive female models in advertisements. These groups of women may be most likely to compare themselves unfavorably with the models, and to 
revise their expectations for their own ideal body-size. This finding is particularly important in that it provides preliminary empirical evidence for the link between advertising, gender-role stereotyping, and eating-disordered behavior.

It is important also to recognize that although women participants were grouped as "high" or "low" in their level of eating problems, even the "high" group had scores that were lower than those with "clinical" eating disorders. It is likely that women with the most severe levels of eating problems would be most negatively impacted by advertisements.

In addition, the links between level of genderstereotyping and impact of advertising suggest that challenging gender-role stereotypes and adopting more egalitarian views of heterosexual relationships may be an effective method for inoculating against the negative effects of advertising. Further, these data provide support for challenging advertisers to use a wider array of bodytypes in their advertisements. Such a shift would likely have an impact on the way women view their bodies and on levels of eating-disordered attitudes and behaviors.

Women and men differed significantly on almost every variable measured. Women reported higher levels of eatingdisordered behavior, more negative attitudes toward their bodies, thinner ideal body-sizes for themselves, less 
endorsement of traditional beauty rituals for women, and lower levels of endorsement of traditional and stereotypical gender-roles than did men. The pursuit of beauty scale measures attitudes about women's beauty, and it is likely that men would score lower on a scale that assessed prescriptions for men's physical attractiveness. In addition, as men typically hold more traditional attitudes toward gender-roles and heterosexual relationships than do women, it is not surprising that they also hold more traditional attitudes about prescriptions for women's beauty. It is important that in this study, a scale was developed to assess this previously unexplored and important element of traditional attitudes.

The only variables on which women and men did not differ were level of global self-esteem, global body satisfaction, and perception of current body-size according to their respective figure-rating scales. The figure-rating scales for women and for men depict a series of 9 comparably sized figures that range from very small to very large. Women and men each placed themselves around figure number 4, slightly less than the mid-sized figure. The finding that women and men did not differ on measures of global selfesteem or global body-satisfaction highlights the importance of using measures that are situationally and contextually specific. Although women and men did not differ on these global measures, they clearly held very different attitudes 
and beliefs about their bodies and the connections between beauty and thinness. Research in the area of eating disorders and the pursuit of thinness should rely more on measures specific to these topics and less on global measures, as these measures contribute little to the understanding of attitudes and behaviors in specific situations and contexts.

Empirical relationships were found to exist between eating-disordered attitudes and behaviors, attitudes consistent with gender-stereotypes, traditional attitudes about gender-roles, beauty-pursuing attitudes and behaviors, attitudes toward one's body, body satisfaction, and selfesteem. However, it is important to note that the patterns and degree of these relationships differed for women and for men. For women, measures of disordered eating were positively correlated with each other and with beauty attitudes and behaviors, and negatively correlated with positive attitudes toward the body, self-esteem, and ideal body-size. They were not correlated with measures of gender stereotyping or endorsement of traditional gender roles. For men, however, measures of eating-disordered behavior were correlated with each other to a lesser degree than for women, and were not correlated with other measures of attitudes about beauty for women, attitudes toward one's own body, and global self-esteem.

The differences found between women's and men's 
correlations suggest that different patterns exist for women and men who exhibit attitudes and behaviors consistent with eating-disorders. That men's level of eating problems did not vary significantly with degree of body-satisfaction, ideal body-size, endorsement of positive attitudes toward the body, or self-esteem, suggests that men with relatively high levels of eating-problems may not have the concomitant body-image and self-esteem problems that women do. Level of body satisfaction was not correlated with global self-esteem in men, whereas it was in women. This finding supports the conclusion although there were no significant differences in self esteem between women and men, level of "global" selfesteem is linked to satisfaction with body size for women. For both women and for men, perception of current bodysize was correlated with ideal body-size. Those participants who perceived themselves as heavier reported heavier ideal body-sizes. However, endorsement of positive attitudes toward the body was negatively correlated with current perception of own body size, though this association was stronger for women than for men. Thus for all participants, perception of oneself as heavier was associated with more negative attitudes about one's body.

For both women and men, positive attitudes toward traditional heterosexual relationships were correlated with endorsement of gender-role-stereotypes. Those women who more strongly supported traditional heterosexual relationships 
were less satisfied with their own bodies. This finding suggests that one method of improving women's satisfaction with their bodies may be to promote relationships with egalitarian, rather than traditional gender-roles.

Positive attitudes about women's traditional beauty rituals were correlated with gender-stereotyping for women and for men, which indicates that individuals of both genders who believe that women should engage in various beauty rituals also believe that women should be traditional in their gender-roles. Women's attitudes about beauty rituals were correlated with the number of beauty behaviors in which they engaged. The more beauty behaviors a woman performed, the thinner she wanted to be. Thus, thinness was viewed as an important element of women's beauty.

Endorsement of traditional beauty attitudes was negatively correlated with women's positive feelings about their bodies. The more a woman believed that all women need to adhere to strict beauty rituals, the more likely she was to hold negative attitudes about her own body.

Preliminary data on the 55-item Pursuit of Beauty Questionnaire supports its validity and utility in exploring relationships between eating problems and general beautypursuits. Exploratory factor analysis revealed 3 factors: "common beauty-pursuing behaviors" (such as cosmetic usage, removal of body-hair, and beauty treatments); "beautypursuing attitudes" (favorable attitudes toward traditional 
beauty rituals for women such as dressing in a feminine manner, pursuing thinness, shaving body-hair, and reading fashion magazines); and "uncommon or expensive beautypursuing behaviors" (such as cosmetic surgery and expensive hair treatments). Once items with loadings less than 0.30 and items that loaded on more than one factor with a loading of .30 or greater are eliminated, 39 items will be retained. This briefer, 39-item scale should be administered to a large sample of young women to determine whether the factor structure remains stable. The current structure should be interpreted with caution because of the relatively small sample size. While the current version of the scale accounted for only $28.42 \%$ of the total variance, this figure is likely to increase following elimination of items with low factor loadings and low part-whole correlations. Some evidence for the construct validity of the scale was provided by its significant correlations with measures of eating-disordered attitudes and behavior, gender stereotyping, body-image and figure ratings of ideal-self. Further, the significant correlations with measures of eating-disordered attitudes and behaviors provide preliminary empirical justification for examining the phenomena of eating disorders within the overall context of the pursuit of beauty.

Recommendations for future research. As the current data cannot be generalized beyond a predominantly European- 
American, heterosexual college sample, future research should focus on extending the results of this study in other samples. In addition, future research should use larger sample sizes in order to increase the power of the design and increase its' sensitivity. As much research in this area has been cross-sectional, longitudinal studies exploring the impact of advertising on women's adherence to gender stereotypes, beauty pursuing attitudes and behaviors, eating attitudes and behaviors, and body image and satisfaction should be conducted. In particular, researchers should examine the impact of level of media exposure on eatingdisordered attitudes and behaviors. Qualitative research with groups of women with varying levels of eatingdisordered behavior is recommended to explore with women the role they think advertising has had on their views about their bodies and their eating behavior. Finally, the preliminary data on the beauty questionnaire are promising, and further work should be done to test it's factor structure, validity, and reliability with larger, more diverse samples.

Conclusions. The results of this study support the proposition that the use of highly attractive and extremely thin models in advertising, in combination with advertisers' promotion of traditional and stereotypical gender-roles, impacts women's views about their bodies. Those women who viewed advertisements depicting models rated their own 
bodies as heavier than those women who viewed advertisements that did not depict models. Although women who did and did not view images of female models did not differ on measures of ideal body-size, body-satisfaction, attitudes toward their bodies, or global self-esteem, it is likely that such a brief exposure in the context of a culture saturated with such images was not sufficient to significantly alter attitudes. College students in particular are exposed to images of extremely thin women in the media on a nearconstant basis. Future research should assess the cumulative impact of such exposure, using a longitudinal design.

Further, the advertising industry's promotion of the pursuit of beauty can be linked to the high incidence of eating problems and body-dissatisfaction in women. Women with high, as compared to low levels of eating-disordered attitudes and behaviors reported having smaller ideal bodysizes following exposure to models in advertisements. These data, in addition to correlations found in this study among measures of traditional beauty attitudes and behaviors and eating-disordered attitudes and behaviors provide empirical links justifying the examination of eating disorders within a the context of women's overall pursuit of beauty. More research is needed to clarify relationships between women's pursuit of beauty and eating-problems, and the scale developed in this study is one tool for such research. In this study, women with high, as compared to low 
levels of adherence to gender stereotypes held more negative attitudes toward their bodies, and among the high eatingdisordered group, were less satisfied with their bodies. In addition, significant correlations were found in this study between a scale assessing women's pursuit of beauty and attitudes consistent with gender stereotypes. Prior research has found that advertisers promote traditional gender-roles (Goffman, 1979; Kilbourne, 1994; Moschis \& Moore, 1982; Peirce, 1990; and Tucker, 1984). Therefore, the high prevalence of eating disorders may be linked not only to advertisers' promotion of thinness and beauty, but to their promotion of traditional gender-roles as well.

Women and men differed significantly on measures of eating attitudes and behavior, adherence to gender stereotypes, and attitudes about women's beauty as well as attitudes toward their bodies. These gender-differences provide additional support for the examination of sociocultural factors in the etiology of eating disorders. In addition, the differing patterns of correlations among these measures between women and men warrants further exploration. These correlations suggest that the etiology and meaning of eating-disordered behavior in samples of women and men may differ. This suggestion is not surprising given the differential treatment of and expectations for women and men in U.S. culture; however, little research has been conducted on the results of such differential treatment as it relates 
to eating disorders.

Overall, the results of this study suggest that greater attention should be paid to the roles of the media and fatoppression when conducting research or working on the prevention and treatment of eating disorders. A shift in focus from models of pathology to prevention and treatment via consciousness raising, political action and societal change is imperative. Directing energy and resources towards challenging fat-oppressive attitudes is likely to have a far greater impact than focusing on individual models of change via psychotherapy, or on ineffective models of change such as dieting. It is already known that weight-loss therapy is frequently ineffective, reinforces cultural stereotypes, may be harmful to women's health, blames individuals for their body-size, and perpetuates fat oppression (Chrisler, 1989). Weight-loss therapy reinforces the cultural stereotype that thinness is equated with beauty and health. In reinforcing this cultural stereotype, weight-loss therapy may actually increase the incidence of eating-problems and bodydissatisfaction. The results of this study provide empirical support for the view that, at least for European-American, heterosexual college women, eating-disordered attitudes and behavior should be viewed in the context of fat oppression and the pursuit of beauty. 


\section{Appendix A \\ CONSENT FORM FOR RESEARCH}

I am at least 18 years old and have been asked to take part in a research project described below. The researcher will explain the project to me in detail. I should feel free to ask questions. If I have more questions later, Lisa Rocchio, the person mainly responsible for this study, (401) 294-4368, will discuss them with me.

This study will examine the relationships among perceptions of the effectiveness of advertisements and attitudes and behaviors in the areas of eating, attractiveness, and self-evaluations. If I choose to participate, I will be asked to attend two one hour sessions over a period of two weeks. At the first session I will be asked to fill out questionnaires about my attitudes and behaviors related to eating, attractiveness, and views of myself. At the second session, I will be asked to view slides of advertisements and to rate them for their sales effectiveness and to complete more questionnaires. In return for my participation, I will earn extra credit in my psychology class.

Some of the questions asked in the questionnaires may result in my experiencing some discomfort; if I wish to speak to someone regarding feelings of discomfort raised in the study I may speak with Lisa Rocchio, M.A., or I may contact the University Counseling Center at 792-2288. 
Although there will be no direct benefit to me for taking part in this study, the researcher may learn more about the impact of advertising on college students and the relationships among certain personal attitudes and behaviors and the perceived sales effectiveness of advertisements.

My participation in this study is both voluntary and anonymous. I will not be asked to provide my name on any document other than the sign up sheet so that I may obtain my extra credit. I will be asked to provide the last four digits of my school identification number so that my responses from parts I and II of the study may be matched. However, I will not be asked to provide information that could identify me personally. At the conclusion of the study I will be offered the opportunity to participate in small, confidential discussion groups to address issues, thought, and feelings raised in the study. My participation in these small groups is voluntary, and my decision whether or not to participate in these small groups will not affect the credit I receive for participation in parts I and II of the study.

I may decide to withdraw from any part of this study at any time, and whatever I decide will in no way affect my grades or my status as a student. The investigator will be available after the testing session to discuss reactions to the study and to questionnaire materials, and will at that time describe more fully the design of the study.

If I have additional questions about this research or 
am not satisfied with the way this study is performed, I may phone Lisa M. Rocchio, M.A., (401) 294-4368, or Bernice Lott, Ph.D. Department of Psychology, (401) 792-4248, anonymously, if I choose. I may also contact the office of the Vice Provost for Research, R. D. Hedlund, 70 Lower College Rd., Kingston, RI (401) 782-8637.

I have read the Consent Form. My questions have been answered. My completion of the questionnaire means that I understand the information and I agree to participate in this study. 


\section{Appendix B}

\section{EATING QUESTIONNAIRE}

INSTRUCTIONS FOR NUMBERS $1-26$ :

Please place an " $X$ " under the column which applies best to each of the numbered statements. All of the results will be anonymous.

Most of the questions directly relate to food or eating, although other types of questions have been included. Please answer each question carefully. Thank you.

\section{Very Some- \\ Always Often Often times Rarely Never}

1. Am terrified about

being overweight.

2. Avoid eating when I am hungry.

3. Find myself preoccupied with food.

4. Have gone on eating binges where I feel that I may not be able to stop.

5. Cut my food into small pieces.

6. Aware of the calorie content of foods that I eat.

7. Particularly avoid foods with a high carbohydrate content (e.g. bread, rice, potatoes, etc.).

8. Feel that others would prefer if I ate more.

9. Vomit after I have eaten.

10. Feel extremely guilty after eating. 


\section{Very Some- \\ Always Often Often times Rarely Never}

11. Am preoccupied with a desire to be thinner.

12. Think about burning up calories when I exercise.

13. Other people think that I am too thin.

14. Am preoccupied with the thought of having fat on my body.

15. Take longer than others to eat my meals.

16. Avoid foods with sugar in them.

17. Eat diet foods.

18. Feel that food controls my life.

19. Display selfcontrol around food.
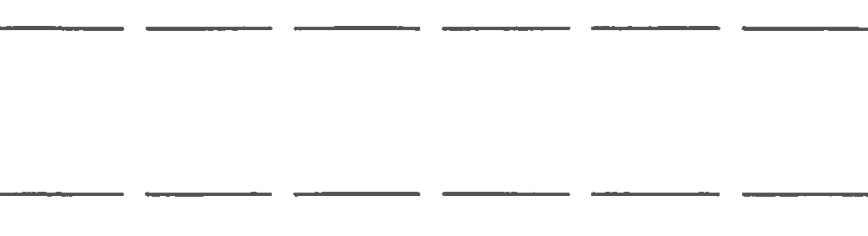

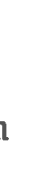
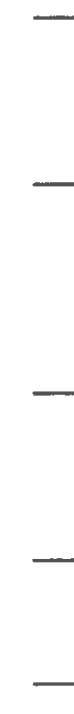

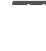
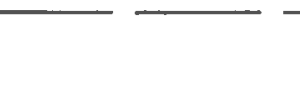

20. Feel that others pressure me to eat.

21. Give too much time and thought to food.

22. Feel uncomfortable after eating sweets.

23. Engage in dieting behavior. 
24. Like my stomach to be empty.

25. Enjoy trying new rich foods.

26. Have the impulse to vomit after meals. 
INSTRUCTIONS FOR NUMBERS 27-62:

Answer each question by circling the appropriate number on this sheet. Please respond to each item as honestly as possible; remember that all of the information you provide will be kept strictly confidential, and there is no way to link your name with your responses.

27. I am satisfied with my eating patterns

1. agree

2. neutral

3. disagree a little

4. disagree

5. disagree strongly

28. Would you presently call yourself a "binge eater"?

1. Yes, absolutely

2. yes

3. yes, probably

4. Yes, possibly

5. no, probably not

29. Do you feel you have control over the amount of food you consume?

1. most or all of the time

2. a lot of the time

3. occasionally

4. rarely

5. never

30. I am satisfied with the shape and size of my body.

1. frequently or always

2. a lot of the time

3. occasionally

4. rarely

5. seldom or never

31. When I feel that my eating behavior is out of control, I try to take rather extreme measures to get back on course (strict dieting, fasting, laxatives, diuretics, self-induced vomiting, or vigorous exercise).

1. always

2. almost always

3. frequently

4. sometimes

5. never or my eating behavior is never out of control 
32. I use laxatives or suppositories to help control my weight.

1. once a day or more

2. 3-6 times a week

3 . once or twice a week

4. 2-3 times a month

5. once a month or less (never)

33. I am obsessed about the size and shape of my body.
1. always
2. almost always
3. frequently
4. sometimes
5. seldom or never

34. There are times when I rapidly eat a very large amount of food.

1. more than twice a week

2. twice a week

3 . once a week

4. 2-3 times a month

5 . once a month or less (or never)

35. How long have you been binge eating (eating uncontrollably to the point of stuffing yourself)?

1. not applicable; I don't binge eat

2. less than 3 months

3. 3 months - 1 year

4. 1 - 3 years

5 . 3 or more years

36. Most people I know would be amazed if they knew how much food I can consume at one sitting.

1. without a doubt

2. very probably

3. probably

4. possibly

5. no

37. I exercise in order to burn calories.

1. more than 2 hours a day

2. about 2 hours per day

3. more than 1 but less than 2 hours per day

4. one hour or less per day

5 . less than once per day or I don't exercise 
38. Compared with others your same sex and age, how preoccupied are you about your weight and body shape?

1. a great deal more than average

2. much more than average

3. more than average

4. a little more than average

5. average or less than average

39. I am afraid to eat anything for fear that I won't be able to stop.
1. always
2. almost always
3. frequently
4. sometimes
5. seldom or never

40. I feel tormented by the idea that I am fat or might gain weight.
1. always
2. almost always
3. frequently
4. sometimes
5. seldom or never

41. How often do you intentionally vomit after eating?
1. 2 or more times a week
2. once a week
3. 2-3 times a month
4. once a month
5. less than once a month or never

42. I eat a lot of food when I'm not even hungry.
1. very frequently
2. frequently
3. occasionally
4. sometimes
5. seldom or never

43. My eating patterns are different from the eating patterns of most people.
1. always
2. almost always
3. frequently
4. sometimes
5. seldom or never 
44. After I binge eat, I turn to one of several strict methods to try to keep from gaining weight (vigorous exercise, strict dieting, fasting, self-induced vomiting, laxatives, or diuretics).

1. never or I don't binge

2. rarely

3. occasionally

4. a lot of the time

5. most or all of the time

45. I have tried to lose weight by fasting or going on strict diets.

1. not in the past year

2. once in the past year

3. 2-3 times in the past year

4. 4-5 times in the past year

5. more than 5 times in the past year

46. I exercise vigorously and for long periods of time in order to burn calories.

1. average or less than average

2. a little more than average

3. more than average

4. much more than average

5. a great deal more than average

47. When engaged in an eating binge, I tend to eat foods that are high in carbohydrates (sweets and starches).
1. always
2. almost always
3. frequently
4. sometimes
5. seldom, or I don't binge

48. Compared to most people, my ability to control my eating behavior seems to be:

1. greater than other's ability

2. about the same

3. less

4. much less

5. I have absolutely no control 
49. I would presently label myself a "compulsive eater" (One who engages in episodes of uncontrolled eating).
1. absolutely
2. yes
3. Yes, probably
4. yes, possibly
5. no, probably not

50. I hate the way my body looks after I eat too much.

1. seldom or never

2. sometimes

3. frequently

4. almost always

5. always

51. When I am trying to keep from gaining weight, I feel that I have to resort to vigorous exercise, strict dieting, fasting, self-induced vomiting, laxatives, or diuretics.
1. never
2. rarely
3. occasionally
4. a lot of the time
5. most or all of the time

52. Do you believe that it is easier for you to vomit than it is for most people?

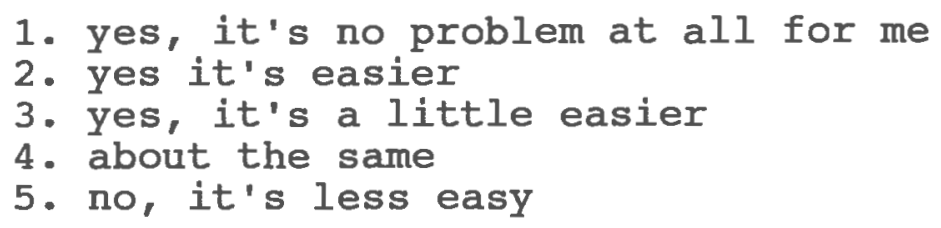

53. I use diuretics (water pills) to help control my weight.
1. never
2. seldom
3. sometimes
4. frequently
5. very frequently

54. I feel that food controls my life.
1. always
2. almost always
3. frequently
4. sometimes
5. seldom or never 
55. I try to control my weight by eating little or no food for a day or longer.
1. never
2. seldom
3. sometimes
4. frequently
5. very frequently

56. When consuming a large quantity of food, at what rate of speed do you usually eat?

1. more rapidly than most people have ever eaten in their lives

2. a lot more rapidly than most people

3. a little more rapidly than most people

4. about the same rate as most people

5. more slowly than most people (or not applicable)

57. I use laxatives or suppositories to help control my weight.
1. never
2. seldom
3. sometimes
4. frequently
5. very frequently

58. Right after I binge eat I feel:

1. so fat and bloated I can't stand it

2. extremely fat

3. fat

4. a little fat

5. OK about how my body looks or I never binge eat

59. Compared to other people of my sex, my ability to always feel in control of how much I eat is:
1. about the same or greater
2. a little less
3. less
4. much less
5. a great deal less 
60. In the last 3 months, on the average how often did you binge eat (eat uncontrollably to the point of stuffing yourself)?

1. once a month or less (or never)

2. 2-3 times a month

3. once a week

4. twice a week

5. more than twice a week

61. Most people I know would be surprised at how fat I look after I eat a lot of food.

1. yes, definitely

2. yes

3. yes, probably

4. yes, possibly

5. no, probably not, or I never eat a lot of food

62. I use diuretics (water pills) to help control my weight.

1. 3 times a week or more

2. once or twice a week

3. 2-3 times a month

4. once a month

5. never 


\section{BEAUTY QUESTIONNAIRE}

Using a scale of $0-7$, please indicate your level of personal interest in the following surgical procedures, i.e., how willing you would be, now or in the future, to undergo the procedure if finances were not a concern.

If you have already had this procedure, circle the type(s) of procedure you have had done.

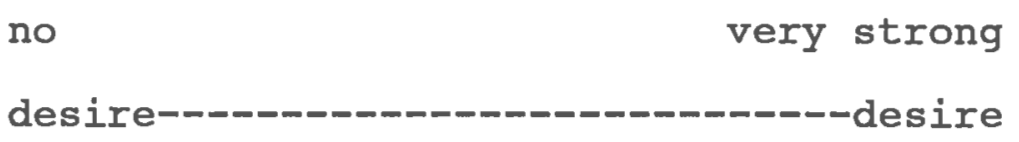
1. Liposuction
$\begin{array}{llllllll}0 & 1 & 2 & 3 & 4 & 5 & 6 & 7\end{array}$

(surgical removal of fat)

$\begin{array}{lllllllll}\text { 2. Eyelid Surgery } & 0 & 1 & 2 & 3 & 4 & 5 & 6 & 7 \\ \text { 3. Rhinoplasty } & 0 & 1 & 2 & 3 & 4 & 5 & 6 & 7\end{array}$

( "nose-job")

4. Breast-enlargement $\quad \begin{array}{lllllllll}0 & 1 & 2 & 3 & 4 & 5 & 6 & 7\end{array}$

5. Collagen injections $\quad \begin{array}{llllllll}0 & 1 & 2 & 3 & 4 & 5 & 6 & 7\end{array}$

(for the face)

6. Retin A for wrinkles $\begin{array}{lllllllll}0 & 1 & 2 & 3 & 4 & 5 & 6 & 7\end{array}$

$\begin{array}{lllllllll}\text { 7. Facelift } & 0 & 1 & 2 & 3 & 4 & 5 & 6 & 7\end{array}$

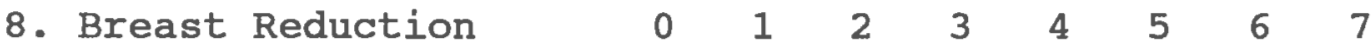

9. Please indicate on a scale from zero to seven the approximate number of fashion magazines that you read on monthly basis; circle the correct number.

$\begin{array}{llllllll}0 & 1 & 2 & 3 & 4 & 5 & 6 & 7+\end{array}$


Using a scale of $0-7$, please circle how regularly you wear the following products:
0 = never
4 = once $\mathrm{a}$ week
1 = once every few months
5 = a few days a week
2 = once every month
6 = almost daily
3 = once every two weeks
7 = daily

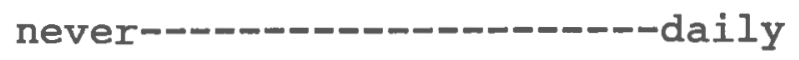

10. Lipstick

11. Eyeliner

12. Eyeshadow

13. Lipliner

14. Foundation

15. Mascara

16. Facial Moisturizer

17. "Cover-up"

18. Blush

19. Perfume

20. Fingernail polish

21. Toenail polish $\begin{array}{llllllll}0 & 1 & 2 & 3 & 4 & 5 & 6 & 7\end{array}$

$\begin{array}{llllllll}0 & 1 & 2 & 3 & 4 & 5 & 6 & 7\end{array}$

$\begin{array}{llllllll}0 & 1 & 2 & 3 & 4 & 5 & 6 & 7\end{array}$

$\begin{array}{llllllll}0 & 1 & 2 & 3 & 4 & 5 & 6 & 7\end{array}$

$\begin{array}{llllllll}0 & 1 & 2 & 3 & 4 & 5 & 6 & 7\end{array}$

$\begin{array}{llllllll}0 & 1 & 2 & 3 & 4 & 5 & 6 & 7\end{array}$

$\begin{array}{llllllll}0 & 1 & 2 & 3 & 4 & 5 & 6 & 7\end{array}$

$\begin{array}{llllllll}0 & 1 & 2 & 3 & 4 & 5 & 6 & 7\end{array}$

$\begin{array}{llllllll}0 & 1 & 2 & 3 & 4 & 5 & 6 & 7\end{array}$

$\begin{array}{llllllll}0 & 1 & 2 & 3 & 4 & 5 & 6 & 7\end{array}$

$\begin{array}{llllllll}0 & 1 & 2 & 3 & 4 & 5 & 6 & 7\end{array}$

$\begin{array}{llllllll}0 & 1 & 2 & 3 & 4 & 5 & 6 & 7\end{array}$ 
Using a scale of $0-7$, please circle the frequency with which you bleach, shave, or otherwise remove body hair from the following areas

$0=$ never

4 = once a week

1 = once every few months 5 = a few days a week or seasonally

2 = once every month

6 = almost daily

3 = once every two weeks

7 = daily

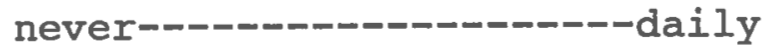

22. Underarms

$\begin{array}{llllllll}0 & 1 & 2 & 3 & 4 & 5 & 6 & 7\end{array}$

23. Bikini Area

$\begin{array}{llllllll}0 & 1 & 2 & 3 & 4 & 5 & 6 & 7\end{array}$

24. Lower Legs

$\begin{array}{llllllll}0 & 1 & 2 & 3 & 4 & 5 & 6 & 7\end{array}$

knee and below

25. Upper Legs

$\begin{array}{llllllll}0 & 1 & 2 & 3 & 4 & 5 & 6 & 7\end{array}$

knee and above

26. Stomach

$\begin{array}{llllllll}0 & 1 & 2 & 3 & 4 & 5 & 6 & 7\end{array}$

27. Upper Lip

$\begin{array}{llllllll}0 & 1 & 2 & 3 & 4 & 5 & 6 & 7\end{array}$

28. Eyebrows

$\begin{array}{llllllll}0 & 1 & 2 & 3 & 4 & 5 & 6 & 7\end{array}$


Using a scale of $0-7$, please circle how often you get the following beauty treatments at a beauty salon or at home ("do it yourself").

$0=$ never or once yearly

4 = once a week

1 = once every few months

5 = a few days a week,

2 = once every month

6 = almost daily

3 = once every two weeks

7 = daily

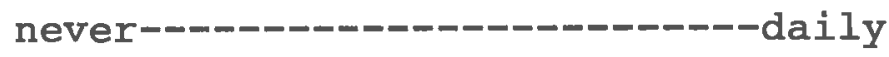

29. Manicure

$\begin{array}{llllllll}0 & 1 & 2 & 3 & 4 & 5 & 6 & 7\end{array}$

30. Pedicure

31. Facial

32. Hair Cuts

$\begin{array}{llllllll}0 & 1 & 2 & 3 & 4 & 5 & 6 & 7\end{array}$

33. Hair Color

$\begin{array}{llllllll}0 & 1 & 2 & 3 & 4 & 5 & 6 & 7\end{array}$

34. Hair permanent $\begin{array}{llllllll}0 & 1 & 2 & 3 & 4 & 5 & 6 & 7\end{array}$

or straightening

$\begin{array}{llllllll}0 & 1 & 2 & 3 & 4 & 5 & 6 & 7\end{array}$

$\begin{array}{llllllll}0 & 1 & 2 & 3 & 4 & 5 & 6 & 7\end{array}$

35. Using a scale of $0-7$, please circle how often you discuss beauty and/or fashion with your friends
$0=$ never or once yearly
4 = once a week
1 = once every few months
5 = a few days a week,
2 = once every month
6 = almost daily
$3=$ once every two weeks
7 = daily

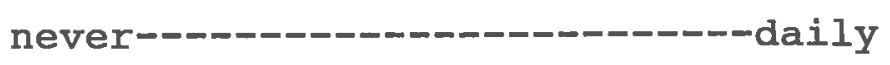

$\begin{array}{llllllll}0 & 1 & 2 & 3 & 4 & 5 & 6 & 7\end{array}$ 
For the following items, please circle your level of agreement with the statements presented using the following scale of one to seven.

1=definitely disagree $5=$ somewhat agree

$2=$ mostly disagree $6=$ mostly agree

$3=$ somewhat disagree $7=$ definitely agree.

$4=$ neither agree nor disagree,

definitely

definitely

disagree agree

36. A woman should do all $\begin{array}{lllllll}1 & 2 & 3 & 4 & 5 & 6 & 7\end{array}$ she can to improve her looks.

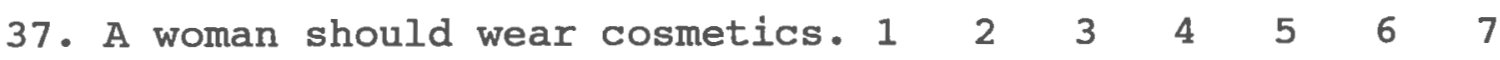

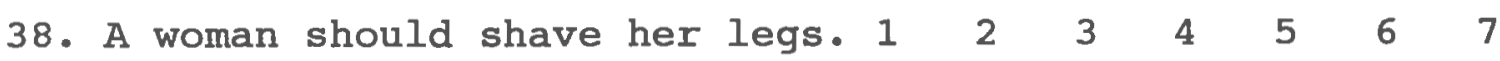
39. It is not important to dress $\begin{array}{llllllll}1 & 2 & 3 & 4 & 5 & 6 & 7\end{array}$ according to current fashion trends.

40. Any woman can look beautiful $11020 \begin{array}{llllll} & 3 & 4 & 5 & 6 & 7\end{array}$ if she tries hard enough.

41. It is not important for a $\begin{array}{lllllll}1 & 2 & 3 & 4 & 5 & 6 & 7\end{array}$ woman to be considered physically attractive by others.

42. A woman should choose her $\begin{array}{lllllll}1 & 2 & 3 & 4 & 5 & 6 & 7\end{array}$ clothing for comfort, not fashion. 


$$
\begin{aligned}
& \text { definitely definitely } \\
& \text { agree------------disagree }
\end{aligned}
$$

43. To keep looking youthful,

$\begin{array}{lllllll}1 & 2 & 3 & 4 & 5 & 6 & 7\end{array}$

a woman should use skin care

products such as

anti-wrinkle creams.

44. A woman should never try to $\quad \begin{array}{lllllllll}1 & 2 & 3 & 4 & 5 & 6 & 7\end{array}$ look like a fashion model.

45. A woman should never have $\quad \begin{array}{llllllll}1 & 2 & 3 & 4 & 5 & 6 & 7\end{array}$ cosmetic surgery to improve her looks.

46. Thin women are more attractive $\begin{array}{llllllll}1 & 2 & 3 & 4 & 5 & 6 & 7\end{array}$ than fat women

46. Dieting to lose weight is a $\quad \begin{array}{llllllll}1 & 2 & 3 & 4 & 5 & 6 & 7\end{array}$ good idea.

48. A woman should exercise

$\begin{array}{lllllll}1 & 2 & 3 & 4 & 5 & 6 & 7\end{array}$ to keep her weight down.

49. A woman should exercise to make her body more sexy.

50. A woman should spend money $\begin{array}{lllllll}1 & 2 & 3 & 4 & 5 & 6 & 7\end{array}$ for professional beauty treatments at a salon to help her to look beautiful.

51. A woman should read fashion $\begin{array}{llllllll}1 & 2 & 3 & 4 & 5 & 6 & 7\end{array}$ magazines 


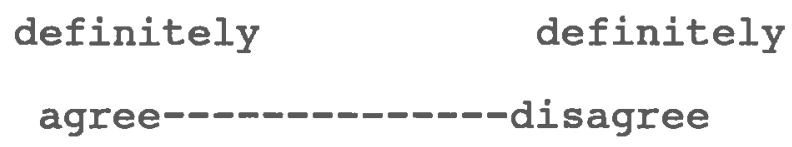

$\begin{array}{lllllllll}\text { 52. A woman should shave under } & 1 & 2 & 3 & 4 & 5 & 6 & 7\end{array}$ her arms.

53. A woman should never let her $\begin{array}{lllllllll}1 & 2 & 3 & 4 & 5 & 6 & 7\end{array}$ boyfriend or partner see her when she is not at her "best".

54. A woman should have long hair.1 $2 \begin{array}{llllll}3 & 4 & 4 & 5 & 6 & 7\end{array}$

$\begin{array}{lllllllll}\text { 55. A woman should always dress } & 1 & 2 & 3 & 4 & 5 & 6 & 7\end{array}$ in a "feminine" manner. 
Please respond to the following items using the following 7 point scale:

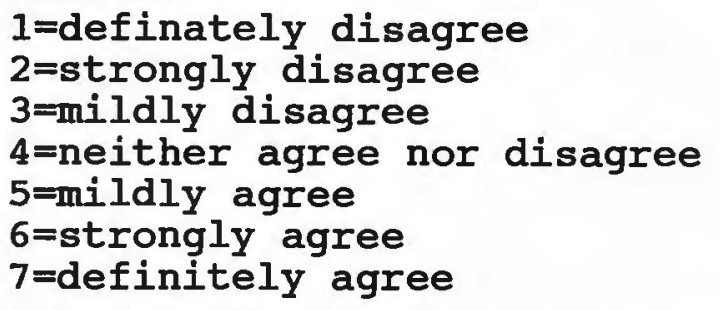

1. A man should fight when the woman he's with is insulted by another man.

2. It is acceptable for the woman to pay for the date.

3. A woman should be a virgin when she marries.

4. There is something wrong with a woman who doesn't want to marry and raise a family.

5. A wife should never contradict her husband in public.

6. It is better for a woman to use her feminine charm to get what she wants rather than ask for it outright.

7. It is acceptable for a woman to have a career, but marriage and family should come first.

8. It looks worse for a woman to be drunk than for a man to be drunk.

9. There is nothing wrong with a woman going to a bar alone.

10. It is just as important to educate daughters as it is to educate sons.

11. Women should be more concerned with clothing and appearance than men.

12. Women should have as much sexual freedom as men.

13. The man should be more responsible for the economic support of the family than the woman. 
14. The belief that women cannot make as good supervisors or executives as men is a myth.

15. The word "obey" should be removed from wedding vows.

16. Ultimately a woman should submit to her husband's decision.

17. Some equality in marriage is good, but by and large the husband ought to have the main sayso in family matters.

18. Having a job is just as important for a wife as it is for her husband.

19. In groups that have both male and female members, it is more appropriate that leadership positions be held by males.

20. I would not allow my son to play with dolls.

21. Having a challenging job or career is as important as being a wife and mother.

22. Men make better leaders.

23. Almost any woman is better off in her home than in a job or profession.

24. A woman's place is in the home.

25. The role of teaching in elementary schools belongs to women.

26. The changing of diapers is the responsibility of both parents.

27. Men who cry have weak character.

28. A man who has chosen to stay home and be a house-husband is not less masculine.

29. As head of the household, the father should have the final authority over the children. 


\section{SELF QUESTIONNAIRE}

Respond to the following items as you feel TODAY AT THIS MOMENT. Please remember that all of your responses will be kept completely confidential.

Please indicate on a scale of one to five your level of agreement with the following statements.

$1=$ definitely disagree

$2=$ mostly disagree

$3=$ neither agree nor disagree

$4=$ mostly agree

$5=$ definitely agree

1. My body is sexually appealing

2. I like my looks just the way they are

3. Most people would consider me good looking

4. I like the way I look without my clothes on

5. I like the way my clothes fit me.

6. I dislike my physique

7. I am physically unattractive

8. I think I am:

1. very underweight

2. somewhat underweight

3. normal weight

4. somewhat overweight

5. very overweight 
9. From looking at me, most other people would think I am:

1. very underweight

2. somewhat underweight

3. normal weight

4. somewhat overweight

5. very overweight

10-18. Use this one to five scale to indicate how satisfied you are with each of the following areas or aspects of your body

$1=$ very dissatisfied

$2=$ mostly dissatisfied,

$3=$ neither satisfied nor dissatisfied

$4=$ mostly satisfied

$5=$ very satisfied.

10. face (facial features, complexion)

11. hair (color, thickness, texture)

12. lower torso (buttocks, hips, thighs, legs)

13. mid torso (waist, stomach)

14. upper torso (chest, breasts, shoulders, arms)

15. muscle tone

16. weight

17. height

18. overall appearance 
Use this one to five scale to indicate your level of agreement with the following statements about yourself:
1. Strongly
2. Agree
3. Disagree
4. Strongly
Agree
Disagree

19. I feel that I'm a person of worth, at least on an equal basis with others.

20. I feel that I have a number of good qualities.

21. All in all, I am inclined to feel that I am a failure.

22. I am able to do things as well as most other people.

23. I feel I do not have much to be proud of.

24. I take a positive attitude toward myself.

25. On the whole, I am satisfied with myself.

26. I wish I could have more respect for myself.

27. I certainly feel useless at times.

28. At times I think I am no good at all.

29. Using a scale of 1 to 10 , with 10 being the most satisfied, and 1 being the least

satisfied, rate your level of body

satisfaction AT THIS MOMENT. 


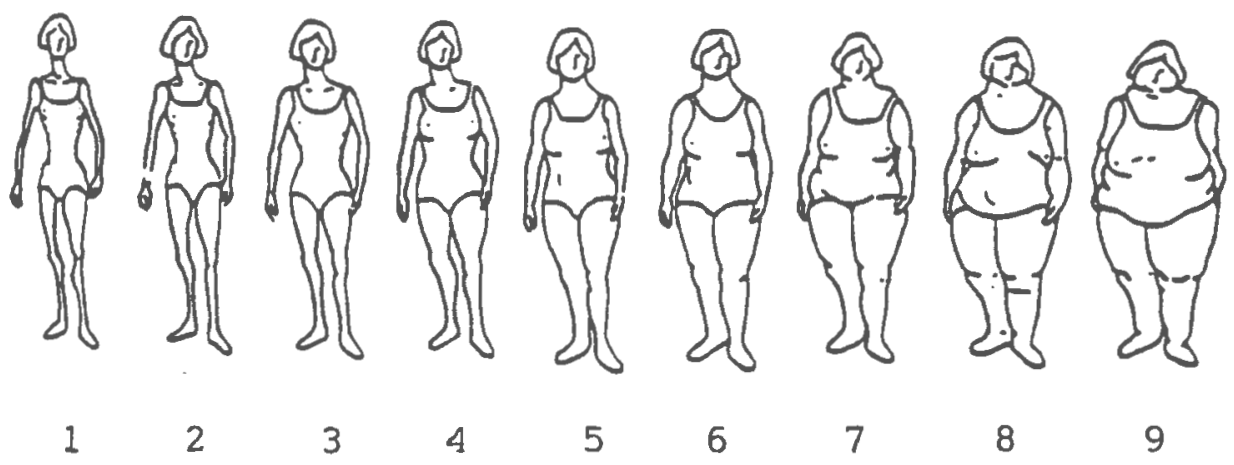

\section{WOMEN RESPONDENTS:}

1. Pick the body that you think is closest to what you look like:

2. Pick the body that you think is closest to what you want to look like:

3. Pick the body that you think is closest to how men want you to look:

\section{MEN RESPONDENTS:}

1. Pick the body that you think is closest to what you want a woman to look like (what you find most attractive): 


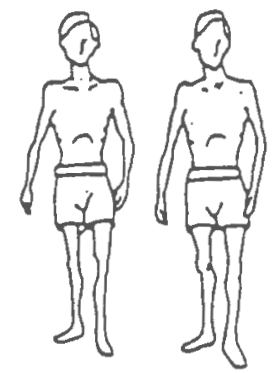

1

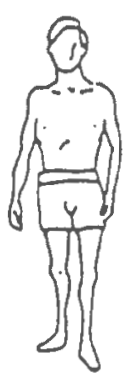

3

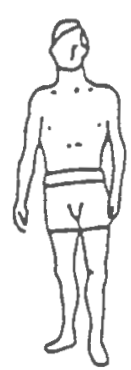

4

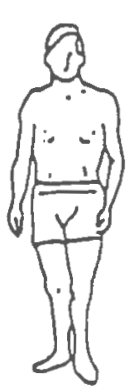

5

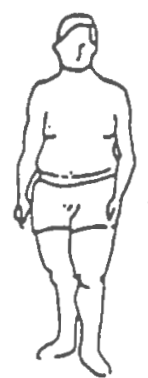

6

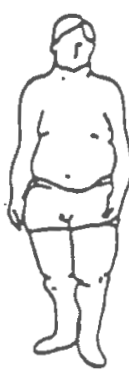

7

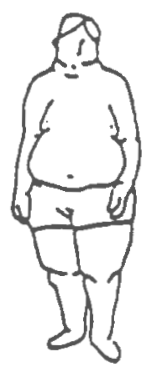

8

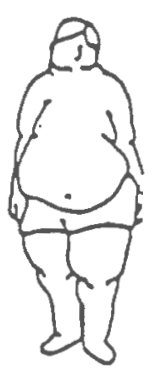

9

\section{MEN RESPONDENTS:}

1. Pick the body that you think is closest to what you look like:

2. Pick the body that you think is closest to what you want to look like:

3. Pick the body that you think is closest to how women want you to look:

\section{WOMEN RESPONDENTS:}

1. Pick the body that you think is closest to what you want a man to look like (what you find most attractive): 


\section{DEMOGRAPHIC QUESTIONNAIRE}

Please circle the number of the correct response or fill in the correct response.

DATE :

TIME :

LAST FOUR DIGITS OF COLLEGE IDENTIFICATION NUMBER:

GENDER

1. Woman

2. Man

$A G E$ :

ETHNICITY

1. African American

2. Asian American

3. European American

SEXUAL ORIENTATION

1. Exclusively Lesbian or Gay

2. Mostly Lesbian or Gay

3. Bisexual

RELATIONSHIP STATUS

1. Single

2. In a committed relationship

3. Living with a romantic partner

YEAR IN COLLEGE

1. First

2. Second

3. Third

4. Fourth
4. Latina/Latino

5. Native American or Alaskan Native

6. Other

4. Mostly Heterosexual

5. Exclusively Heterosexual
4. Married

5. Divorced or Separated
5. Graduate Student

6. Non-matriculated

MAJOR: 


\section{BIBLIOGRAPHY}

Abrams, K. K., Allen, L. R., \& Gray, J. J. (1993).

Disordered eating attitudes and behaviors, psychological adjustment, and ethnic identity: A comparison of black and white female college students. International Journal of Eating Disorders, 14, 49-57.

Adler, R. P. \& Faber, R. J. (1980). Background "Children's television viewing patterns. In R.P. Adler, J. S. Lesser, L. K. Meringoff, T. S. Tobertson, J. T. Rossiter, And S. Ward (Eds.), The effects of television advertising on children: Review and recommendations. Lexington, MA: Lexington Books.

Agell, G. \& Rothblum, E. (1991). Effects of clients' obesity and gender on the therapy judgments of psychologists. Professional Psychology Research and Practice, 22, 223229 .

Allon, N. (1976). Tensions in interactions of overweight adolescent girls. Women \& Therapy, 1, 14-15, 18-23. American Psychiatric Association. (1987). Diagnostic and statistical manual of mental disorders (3rd ed., revised). Washington, DC: Author.

Bennet, w. \& Gurin, J. (1982). The Dieter's Dilemma. New York: Basic Books.

Berg, K. (1988). The prevalence of eating disorders in co-ed versus single-sex residence halls. Journal of College Student Development, 29, 125-131. 
Brand, P. A., Rothblum, E. D., \& Solomon, I. J. (1992). A comparison of lesbians, gay men, and heterosexuals on weight and restrained eating. International Journal of Eating Disorders, 11, 253-359.

Brown, L. S. (1989). Fat-oppressive attitudes and the feminist therapist: Directions for Change. Women \& Therapy, $8,19-30$.

Brown, L. S. \& Rothblum, E. (1989). Editorial statement. Women \& Therapy, $\underline{8}, 1-3$. Brown, T. A., Cash, T. F., \& Mikulka, P. J. (1990). Attitudinal body-image assessment: Factor analysis of the Body-Self Relations Questionnaire. Journal of Personality Assessment, 55, 135-144. Brownell, K. D. (1991). Dieting and the search for the perfect body: Where physiology and culture collide. Behavior Therapy, 22, 1-12. Burt, M. (1980). Cultural myths and supports for rape. Journal of Personality and Social Psychology, 38, 217230 .

Button, E., \& Whitehouse, A. (1981). Subclinical anorexia nervosa. Psychological Medicine, 11, 509-516. Cahnman, W. J. (1968). The stigma of obesity. The Sociological Quarterly, 9, 283-299. Canning, H. \& Mayer, J. (1966). Obesity-its possible effect on college acceptance. New England Journal of Medicine, 25, 1172-1174. 
Cash, T. F. (1990). The Multidimensional Body-Self Relations Questionnaire. Unpublished test manual, old Dominion University, Norfolk, VA. (Available on request from the author).

Cash, T. F., Cash, D. W., \& Butters, J. W. (1983). Mirror, mirror, on the wall... . Contrast effects and selfevaluations of physical attractiveness. Personality and Social Psychology Bulletin, 9, 351-358.

Cash, T. F., Winstead, B. A., \& Janda, L. H. (1985). Your body, yourself: A reader survey. Psychology Today, $\underline{19}(7), 22-26$.

Cash, T. F., Winstead, B. A., \& Janda, L. H. (1986). Body image survey report: The great American shape-up. Psychology Today, $\underline{20}(4), 30-44$.

Chrisler, J. C. (1989). Should feminist therapists do weight loss counseling? Women and Therapy, $\underline{8}, 31-37$.

Cogan, J. C., Bhalla, S. K., Sefa-Dedeh, A., \& Rothblum, E. D. (in press). A comparison study of United States and African students on perceptions of obesity and thinness. Journal of Cross Cultural Psychology.

Cogan, J. C. \& Rothblum, E. D. (1992). Outcomes of weight loss programs. Genetic, Social, and General Psychology Monographs, 118, 387-415.

Crandall, C. S. (1991). Do heavyweight students have more difficulty paying for college? Personality and Social Psychology Bulletin, 17, 606-611. 
Downs, A. C. \& Harrison, S. K. (1985). Embarrassing age spots or just plain ugly? Physical attractiveness stereotyping as an instrument of sexism on American television commercials. Sex Roles, 13, 9-19. Dworkin, S. (1989). Not in man's image: Lesbians and the cultural oppression of body image. Women \& Therapy, $\underline{8}$, 27-38.

Ernsberger, P\& Haskew, P. (1987). Rethinking obesity: An alternative view of its health implications. Journal of Obesity and Weight Regulation, $\underline{6}, 1-81$. Fallon, A. E., \& Rozin, P. (1985). Sex differences in perceptions of desirable body shape. Journal of Abnormal Psychology, 94, 102-105.

Faludi, S. (1991). Backlash: The undeclared war against

American women. New York: Crown. Fitzgerald, F. T. (1981). The problem of obesity. Annual Review of Medicine, 32, 221-231. Freedman, R. (1986). Beauty bound. Lexington, MA: Lexington Books.

Garner, D., \& Garfinkel, P. (1979). The Eating Attitudes Test: An index of symptoms of anorexia nervosa. Psychological Medicine, 9, 273-279. Garner, D. \& Garfinkel, P. (1980) Sociocultural factors in the development of anorexia nervosa. Psychological Medicine, 10, 647-656.

Garner, D. M., Garfinkel, P. E., Schwartz, D., \& Thompson, 
M. (1980). Cultural expectation of thinness in women. Psychological Reports, 47, 483-491.

Garner, D., Olmsted, M., Bohr, Y., \& Garfinkel, P. (1982). The Eating Attitudes Test: Psychometric features and clinical correlates. Psychological Medicine, 12, 1-8. Gettelman, T. E. \& Thompson, J. K. (1993). Actual

differences and stereotypical perceptions in body image and eating disturbance: A comparison of male and female heterosexual and homosexual samples. Sex Roles, $\underline{29}, 545-562$.

Gibbs, R. E. (1986). Social factors in exaggerated eating behavior among high school students. International Journal of Eating Disorders, $5,1103-1107$. Goffman, E. (1979). Gender advertisements. New York: Harper \& Row.

Gowers, S. \& McMahon, J. B. (1989). Social class and prognosis in anorexia nervosa. International Journal of Eating Disorders, $8,105-109$. Greenfeld, D., Quinlan, D. M., Barding, P., Glass, E., \& Bliss, A. (1987). Eating behavior in an adolescent population. International Journal of Eating Disorders, 6, 99-111.

Irving, L. M. (1990). Mirror images: Effects of the standard of beauty on the self- and body-esteem of women exhibiting varying levels of bulimic symptoms. Journal of Social and Clinical Psychology, $9,230-242$. 
Karris, I. (1977). Prejudice against obese renters. The Journal of Social Psychology, 101, 159-160. Kenrick, D. T. \& Gutierres, S. E. (1980). Contrast effects and judgments of physical attractiveness: when beauty becomes a social problem. Journal of Personality and Social Psychology, 38, 131-140. Kenrick, D. T., Gutierres, S. E., \& Goldberg, I. L. (1989). Influence of popular erotica on judgments of strangers and mates. Journal of Social Experimental Psychology, 25, 159-167.

Kilbourne, J. (1994). Still killing us softly: Advertising and the obsession with thinness. In P.Fallon, M. Katzman, and S. Wooley (Eds), Feminist perspectives on eating disorders (pp. 395-418). New York: The Guilford Press. Koslowsky, M., Scheinberg, A., Bleich, A., Mark, M., Apter, A., Danon, Y., \& Solomon, Z. (1992). The factor structure and criterion validity of the short form of the Eating Attitudes Test. Journal of Personality Assessment, $\underline{58}$, 27-35.

Larkin, J. C. \& Pines, H. A. (1979). No fat persons need apply. Sociology of Work and Occupations, 6 312-327. Larson, K. S. \& Long, E. (1988). Attitudes toward sex-roles: Traditional or egalitarian? Sex Roles, 19, 1-12. Levenkron, S. (1982). Treating and overcoming Anorexia Nervosa. New York: Warner Books. Lissner, I., Odell, P. M., D'Agostino, R. B., Stokes, J., 
Kreger, B. E., Belanger, A. J., \& Brownell, K. D. (1991). Variability of body weight and health outcomes in the Framingham population. New England Journal of Medicine, 324, 1839-1844.

Maiman, L. A., Becker, M. H., \& Finlay, J. (1979). Attitudes toward obesity and the obese among professionals. Research, 74, 331-336.

Miller, C. T. \& Rothblum, E. D. (1990). Social interactions of obese and nonobese women. Journal of Personality, $\underline{58}$, 365-380.

Mintz, L. B., \& Betz, N. E. (1988). Prevalence and correlates of eating disordered behaviors among undergraduate women. Journal of Counseling Psychology, 35, 463-471.

Moschis, G. P. \& Moore, R. L. (1982). A longitudinal study of television advertising effects. Journal of Consumer Research, 9, 279-286.

Packer, J. (1989). The role of stigmatization in fat people's avoidance of physical exercise. Women \& Therapy, $\underline{8}, 49-63$.

Peirce, K. (1990). A feminist theoretical perspective on the socialization of teenage girls through seventeen magazine. Sex Roles, 23, 491-500.

[Polivy, J. \& Herman, C. P. (1983). Breaking the diet habit: The natural weight alternative. New York: Basic Books. Eolivy, J. \& Herman, C. P. (1987). Diagnosis and treatment 
of normal eating. Journal of Consulting and Clinical Psychology, 55, 635-644.

Pumariega, A. J. (1986). Acculturation and eating attitudes in adolescent girls: A comparative and correlational study. Journal of the American Academy of Child Psychiatry, 25, 276-279

Raciti, M. \& Norcross, J. (1987). The EAT and EDI:

Screening, interrelationships, and psychometrics. International Journal of Eating Disorders, $\underline{6}$, 579-586. Rand, C. S. W. \& Kuldau, J. M. (1992). Epidemiology of bulimia and symptoms in a general population: Sex, age, race, and socioeconomic status. International Journal of Eating Disorders, 11, 37-44.

Richins, M. L. (1991). Social comparison and the idealized images of advertising. Journal of Consumer Research, 18, 71-83.

Robinson, J. P. \& Shaver, P. R. (1973). Measures of social psychological attitudes. Survey Research Center, Institute for Social Research, Ann Arbor, MI: University of Michigan.

Rodin, J., Silberstein, L., \& Striegel-Moore, R. (1984). Women and weight: A normative discontent. Nebraska Symposium on Motivation, 32, 267-307.

Root, M. P. P. (1990). Disordered eating in women of color. Sex Roles, 22, 525-536.

Rosenberg, M. (1965). Society and the adolescent self-image. 
Princeton, N.J.: Princeton University Press. Rosenzweig, M. \& Spruill, J. (1987). Twenty years after twiggy: A retrospective investigation of bulimic-like behaviors. International Journal of Eating Disorders, $\underline{6}$, 59-65.

Rossi, J. \& Gibbs, R. (1986). Factor structure of the Eating Attitudes Test: Changes in dieting behavior through adolescence. Paper presented at the 57th annual meeting of the Eastern Psychological Association, New York, NY. Rothblum, E. (1990). Women and weight: Fad and fiction. Journal of Psychology, 124, 5-24. Rothblum, E. (1992). The stigma of women's weight: Social and economic realities. Feminism \& Psychology, 2, 61-73. Rothblum, E. (1994). "I'll die for the revolution but don't ask me not to diet": Feminism and the continuing stigmatization of obesity. In P. Fallon, M Katzman, \& S. Wooley (Eds.), Feminist perspectives on eating disorders (pp. 53-76). New York: The Guilford Press. Rothblum, E. D., Miller, C. T., \& Barbutt, B. (1988). Stereotypes of obese female job applicants. International Journal of Eating Disorders, I, 277-283.

Saltzberg, E. A. \& Chrisler, J. C. (1994). Beauty is the beast: Psychological effects of the pursuit of the perfect female body. In J. Freeman (Ed.), Women: A feminist perspective (5th ed.) (pp. 306-315). Mountain View, CA: Mayfield. 
Seid, R. P. (1994). Too "close to the bone": The historical context for women's obsession with slenderness. In P. Fallon, M. A. Katzman, \& S. C. Wooley (Eds.), Feminist Perspectives on Eating Disorders (pp. 3-16). New York: The Guilford Press.

Silber, E., \& Tippett, J. (1965). Self-esteem: Clinical assessment and measurement validation. Psychological Reports, 16, 1017-1071. Smith, J. E., \& Krejci, J. (1991). Minorities join the majority: Eating disturbances among Hispanic and Native American youth. International Journal of Eating

Disorders, 10, 179-186.

Smith, M. \& Thelen, M. H. (1984). Development and validation of a test for bulimia. Journal of Consulting and Clinical Psychology, 52, 863-872.

Sobal, J. \& Stunkard, A. J. (1989). Socioeconomic status and obesity: A review of the literature. Psychological Bulletin, 105, 260-275.

Spillman, D. M. \& Everington, C. (1989). Somatotypes revisited: Have the media changed our perception of the female body image? Psychological Reports, 64, 887-890. Stake, J. \& Lauer, M. L. (1987). The consequences of being overweight: A controlled study of gender differences. Sex Roles, 17, 31-47.

Steinem, G. (1994). Moving beyond words. New York: Simon and Schuster. 
Stunkard, A. J. (1958). The results of treatment for obesity. New York State Journal of Medicine, 58, 79-87. Swartz, L. (1985). Anorexia nervosa as a culture-bound syndrome. Society of Scientific Medicine, 20, 725-730. Thelen, M. H., Farmer, J., Wonderlich, S., \& Smith, M. (1991). A revision of the Bulimia Test: The BULIT-R. Psychological Assessment, $\underline{3}, 119-124$. Thompson, J. K. (1986). Larger than life. Psychology Today, April, 41-44. Thompson, M., \& Schwartz, D. (1982). Life adjustment of women with anorexia nervosa and anorexia nervosa-like behavior. International Journal of Eating Disorders, 1 , $47-60$

Tiggeman, M. \& Rothblum, E. D. (1988). Gender differences in social consequences of perceived overweight in the United States and Australia. Sex Roles, 18, 75-86. Tucker, C. M. (1984). Distortions in advertising: The trivialization of American women. Social Action and the Law, 10, 12-20. Welch, G., Thompson, A., \& Hall, A. (1993). The BULIT-R: Its reliability and clinical validity as a screening tool for DSM-III-R bulimia nervosa in a female tertiary education population. International Journal of Eating Disorders, 14, 95-105. Wiseman, C. V., Gray, J. J., Mosimann, J. E., \& Ahrens, A. H. (1992). Cultural expectations of thinness in women: An 
update. International Journal of Eating Disorders, 11, 85-59.

Wolf, N. (1991). The beauty myth: How images of beauty are used against women. New York: William Morrow. Wood, J. V. (1989). Theory and research concerning social comparisons of personal attributes. Psychology Bulletin, $\underline{106}, 231-348$.

Wooley, S. C. \& Wooley, O. W. (February, 1984). Feeling fat in a thin society. Glamour.

Young, L. M. \& Powell, B. (1985). The effects of obesity on the clinical judgments of mental health professionals. Journal of Health and Social Behavior, 26, 233-246. 